ISSN: 0213-2079 - ISSN electrónico: 2386-3889

DOI: https://doi.org/10.14201/shhmo2017391369402

\title{
ABASTO, PRECIOS Y CONSUMO DE VINO EN UNA VILLA CASTELLANA: EL BURGO DE OSMA, 1655-1804
}

\section{Supply, Prices and Consumption of Wine in a Castilian Town: El Burgo de Osma, 1655-1804}

Emilio PÉREZ ROMERO

Universidad Complutense de Madrid

Correo-e: emilio.perez@ccee.ucm.es

RESUMEN: El estudio de la producción, la distribución y el consumo de vino en la España moderna, dada la naturaleza de las fuentes disponibles, debe abordarse, en buena medida, a través del análisis de casos locales. Este trabajo se centra en el mercado de la villa de El Burgo de Osma (Soria) entre mediados del siglo XVII y comienzos del XIX. La fuente principal es la documentación relacionada con la administración de las tabernas municipales. En relación con el funcionamiento de dicho mercado, se presta especial atención a los mecanismos de abastecimiento, la composición y la evolución de los precios, y los cambios que se produjeron en el área de aprovisionamiento en el transcurso del siglo XviII. También se proporciona nueva información sobre la trayectoria de la producción de vino en la Ribera del Duero en el mismo periodo.

Palabras clave: vino; mercado; precios; Castilla; siglo xviII.

ABSTRACT: The study of the production, distribution and consumption of wine in modern Spain, given the nature of the available sources, must be addressed, largely through the analysis of local cases. This work focuses on the market of the town of El Burgo de Osma (Soria) between the mid-seventeenth century and early nineteenth centuries. The main data source is related to the administration of municipal taverns. In connection with the operation of the market, special attention to the mechanisms

(C) Ediciones Universidad de Salamanca / ®@ Stud. his., H. ${ }^{a}$ mod., 39, n. 1 (2017), pp. 369-402 
of supply, the composition and evolution of prices, and the changes that occurred in the supply area during the eighteenth century it is provided. New information about the history of wine production in the Ribera del Duero in the same period is also supplied.

Key words: Wine; Market; Prices; Castile; Eighteenth Century.

\section{INTRODUCCIÓN}

El vino merece una especial atención en el estudio de la economía española de la época moderna por, al menos, cuatro razones: $1^{\circ}$ ) su elevado contenido calórico lo convertía en un importante componente de la dieta ${ }^{1} ; 2^{\circ}$ ) era objeto de transacción comercial -es decir, pasaba por el mercado- en mayor medida que otros productos agrarios, como el trigo, las legumbres o, incluso, la carne; $3^{\circ}$ ) desde comienzos del siglo XVII, se convirtió en uno de los bienes cuyo consumo soportó una mayor carga fiscal, y $4^{\circ}$ ) en muchas comarcas la viticultura constituía una de las pocas vías practicables para intensificar la producción agraria. Las relaciones entre el aumento de la presión tributaria, el consumo de vino y el cultivo de la vid han sido objeto de recientes análisis con resultados contradictorios. Así, los últimos trabajos sobre Madrid sostienen que, en el transcurso del siglo xviI, el aumento de los impuestos, si bien dio lugar a profundas transformaciones en el mercado del vino, estimulando el fraude, no redujo significativamente el consumo per cápita y, de hecho, el cultivo de la vid aumentó en torno a la capital ${ }^{2}$. En consecuencia,

1. No en vano, en la elaboración de índices de precios, se le suele asignar una ponderación significativa en la cesta de la compra de alimentos, aunque quizá inferior a la que merecería. En los últimos índices de precios construidos para Madrid y Sevilla, el vino ocupa, dentro de la partida de alimentación, el tercer lugar por orden de importancia (12-13\%), tras el pan (36\%) y la carne (24-25\%): Llopis, E.; García-Hiernaux, A.; García Montero, H.; González Mariscal, M. y Hernández García, R.: «Índices de precios de tres ciudades españolas, 16801800", América Latina en la Historia Económica, 32, 2009, pp. 39-40; Llopis, E. y GARcía Montero, H.: «Precios y salarios en Madrid, 1680-1800», Investigaciones de Historia Económica, 7, 2011, p. 298; Llopis, E. y GonZÁlez MARISCAL, M.: «Un crecimiento tempranamente quebrado: el producto agrario en Andalucía occidental en la Edad Moderna», Historia Agraria, 50, 2010, p. 18 (nota 16).

2. Andrés, J. I.: «¿Quién pagó los tributos en la Castilla del siglo XviII? El impacto de los tributos sobre el vino en Madrid», Studia Historia. Historia Moderna, 32, 2010, pp. 229-257; ANDRÉs, J. I.: «Fiscalidad y precios en Castilla en el siglo XvII: los precios del vino en Madrid, 1606-1700», Revista de Historia Económica, XXIX, 2, 2011, pp. 269-298; ANDrÉs, J. I.: «Los precios del vino ordinario en el Madrid del siglo xviı», en Marcos Martín, A.: (ed.). Hacer historia desde Simancas. Homenaje a José Luis Rodríguez de Diego. Valladolid, 2011, Junta de

(C) Ediciones Universidad de Salamanca / ®@ Stud. his., H. ${ }^{a}$ mod., 39, n. 1 (2017), pp. 369-402 
el impacto de la fiscalidad sobre la viticultura habría sido nulo o relativamente moderado. Sin embargo, otros autores achacan precisamente a esa fiscalidad una contracción de la producción vitícola, tanto en términos absolutos como relativos, con importantes y duraderos efectos sobre algunas economías regionales ${ }^{3}$.

El estudio de la producción, la comercialización y el consumo del vino está plagado de dificultades. La información cuantitativa de que disponemos se reduce, casi exclusivamente, a series locales de diezmos y, sobre todo, de precios, y unas y otras adolecen de graves insuficiencias. De entrada, han de tenerse en cuenta tanto la distinción, no siempre bien especificada, entre mosto y vino, como la diversidad de las unidades de medida utilizadas ${ }^{4}$. Por lo que se refiere a los registros diezmales, al tratarse de un producto de manejo relativamente complejo y delicado, los grandes perceptores de diezmos, como obispos y cabildos catedralicios, solían arrendar su recaudación, lo que, como es sabido, complica enormemente la interpretación de los datos y, por lo tanto, dificulta la obtención de series a una escala superior a la parroquial. Además, muy probablemente, también era más fácil la defraudación en el pago de los diezmos de mosto y de vino que en los de cereales. En el ámbito de los precios, se deben distinguir los precios de venta de los vinicultores (o de los perceptores de rentas o diezmos en vino) a los intermediarios (arrieros, taberneros o mesoneros) de los precios de venta de estos a los consumidores, y, también, se ha tener en cuenta si se trata de precios de venta al por mayor o al por menor. Asimismo debe calibrarse la incidencia sobre unos y otros de las cargas tributarias. Por otro lado, la mayor parte de los datos disponibles proceden de fuentes urbanas, fundamentalmente de libros de contabilidad de instituciones religiosas, asistenciales o educativas, que a veces compraban al por mayor o se beneficiaban de privilegios fiscales, lo que introduce sesgos que invitan a la prudencia a la hora de generalizar sus conclusiones al conjunto de una economía básicamente rural. Finalmente, el vino es un producto enormemente heterogéneo y fácil de

Castilla y León, pp. 53-72. El fraude se habría producido por una doble vía: el deterioro de la calidad del vino vendido en las tabernas y el aumento de la comercialización al margen de los cauces establecidos.

3. Para Castilla-La Mancha, Sebastían, J. A.; García Montero, H.; Zafra, J. y BernarDos, J. U.: «Del crecimiento a la decepción. La producción agraria en Castilla la Mancha en la Edad Moderna. Una primera aproximación», IX Congreso de la AEHE. Sesión A1. El PIB y las macromagnitudes económicas en la España del Antiguo Régimen (Murcia, 10-12 de septiembre de 2008), pp. 18-19. Para Andalucía, Llopis, E. y González Mariscal, M.: «Un crecimiento tempranamente quebrado», pp. 23, 26-28, 32 y 34-36.

4. La capacidad de la cántara, una de las unidades más usadas para medir cantidades de mosto y vino, era más diversa y variable de lo que se suele suponer. A lo que se añade la dificultad de sus medidas sisadas.

(C) Ediciones Universidad de Salamanca / ®@ Stud. his., H. ${ }^{a}$ mod., 39, n. 1 (2017), pp. 369-402 
adulterar, lo que convierte en poco menos que ilusoria la pretensión de obtener series largas de precios para vinos de calidad uniforme.

\section{2. ОвJETIVOS y FUENTES}

Este trabajo aborda el análisis del mercado del vino en la zona oriental de Castilla la Vieja a dos escalas diferentes. La primera es la microeconómica, analizando el caso de una villa castellana, a la que se refiere el grueso de la información cuantitativa. La segunda, a partir de los resultados obtenidos en la anterior, abre el foco y trata de captar algunos de los cambios que pudieron afectar a la producción y al comercio de vino en la encrucijada entre las dos Castillas y Aragón durante la segunda mitad del siglo xviII.

En definitiva, dada la ausencia de fuentes que permitan abordar globalmente el funcionamiento del mercado del vino durante la Edad Moderna, con este método se intenta, a partir de la descripción densa y el análisis de un caso local, no solo proporcionar nueva evidencia empírica, sino también esclarecer algunas cuestiones de alcance más amplio y formular hipótesis que puedan orientar futuras investigaciones.

La fuente principal la constituyen las cuentas anuales de las tabernas municipales de El Burgo de Osma (Soria), de las que -junto con otra documentación relativa a las mismas- se ha conservado un buen número para el periodo que va desde la cuarta década del siglo xvir hasta la tercera del xix, si bien solo es posible reconstruir series ininterrumpidas entre 1685 y $1804^{5}$. Hasta finales de la década de 1730 las cuentas ofrecen una información muy detallada: en cada una de las entradas de vino asentadas en la data se indica el tipo de caldo (tinto o blanco), el lugar de procedencia, el precio en origen y el coste del transporte; y en las del cargo, los precios de venta ${ }^{6}$. Lamentablemente, después solo se identifica genéricamente la zona -o zonas- de procedencia del vino -no el lugar concreto, como se había hecho con anterioridad $-\mathrm{y}$ todos los costes aparecen agregados. No obstante, para algunos ejercicios de la segunda mitad del siglo xviII se han conservado los denominados libros de tabernas en los que se iban anotando las partidas de vino que se descargaban diariamente en cada una ellas, haciendo constar -aquí sí- el lugar de origen, el nombre del transportista, el coste por arroba y el precio de venta por azumbre. Aunque no se distingue en cada partida el precio en origen y el coste del

5. Archivo Municipal de El Burgo de Osma [en adelante AMBO], legs. 557, 610, 613, 615 y 618.

6. Todos los precios aparecen siempre en maravedís o reales por arroba, lo que elimina el enojoso problema que, a veces, plantean los azumbres sisados.

(C) Ediciones Universidad de Salamanca / ®@ Stud. his., H. ${ }^{a}$ mod., 39, n. 1 (2017), pp. 369-402 
transporte, cabe desagregar ambos componentes porque en las primeras páginas de los libros figura una relación de los portes para cada zona por arroba y legua, así como las distancias entre El Burgo y cada uno de los pueblos de procedencia del vino. El principal inconveniente de estos libros es que obligan a procesar los datos de cientos de descargas para poder obtener la información global de un solo año. Las cuentas generales de la villa y los libros de actas constituyen la principal documentación complementaria. También se utiliza nueva información diezmal relativa a la producción de vino en la Ribera del Duero.

\section{El mercado del vino en El Burgo de Osma}

El Burgo de Osma, sede episcopal de la diócesis de Osma, era una villa de tamaño modesto. El Catastro de Ensenada registra una población de 1.512 personas, de las cuales 129 pertenecían al estado eclesiástico, con las que residían otras 155 en calidad de parientes o de sirvientes. El resto se distribuían en 322 familias, de las que 53 eran de viudas y/o pobres. De los 269 «cabezas de familia» seglares y activos, solo 41 figuran expresamente con ocupaciones del sector primario (20 hortelanos, 11 pastores y 10 labradores $)^{7}$. En consecuencia, aun en el caso de que todos los que aparecen registrados como jornaleros (48) trabajaran en la agricultura o la ganadería -lo que es harto improbable-, cuando menos dos tercios de los vecinos se empleaban en actividades manufactureras y de servicios. Esta estructura ocupacional daba a la villa un acusado perfil urbano, al menos como mercado de alimentos. El Burgo creció durante la segunda mitad del siglo xvirI: en 1787 el número de habitantes ya ascendía a $2.167^{8}$.

Las instituciones propias de una sede diocesana -ante todo el obispado y la catedral, pero también el seminario, el colegio de Santa Catalina y un convento de carmelitas-, perceptoras de cuantiosas rentas decimales y fundiarias procedentes de toda la diócesis, constituían el motor de la actividad económica de la localidad. Más allá de que un porcentaje significativo de los «cabezas de familia» (al menos, un $12 \%$ ) trabajaran directamente para las instituciones eclesiásticas, buena parte de la industria y de los servicios se orientaban a satisfacer la demanda del clero.

Una peculiaridad de El Burgo de Osma era la estrechez de su término municipal, «tan limitado», según Madoz, que podía recorrerse en poco más de un cuarto

7. Dos de los labradores tenían, además, otra ocupación: cochero y mercader, respectivamente.

8. El número de habitantes en 1751 se ha obtenido a partir del libro de «cabezas de casa» del Catastro de Ensenada (Archivo Histórico Provincial de Soria) y el de 1787 del Censo de Floridablanca. El crecimiento demográfico de la villa parece deberse en buena medida a la inmigración.

(C) Ediciones Universidad de Salamanca / ®@ Stud. his., H. ${ }^{a}$ mod., 39, n. 1 (2017), pp. 369-402 
de hora de este a oeste y en media hora de norte a sur'. Su superficie cultivada, a mediados del siglo xviII no excedía de las 1.400 fanegas de sembradura, unas 375 hectáreas, que venían a representar, aproximadamente, la mitad del término; el resto se repartía entre un monte cuya única utilidad radicaba en el pasto, dedicado a la alimentación del ganado que se compraba para el abasto de la carnicería, y tierras «yermas e inútiles». La cabaña ganadera local tampoco era grande, aunque de cara a su sustento la cortedad del término se veía paliada por la posibilidad de acceder a los pastos de pueblos comuneros con los que había concordias a tal efecto. Las respuestas a las preguntas $18^{\mathrm{a}}$ y $20^{\mathrm{a}}$ del Interrogatorio general del Catastro de Ensenada computan, entre reses adultas y crías, 4.206 cabezas de ganado lanar, 478 de cabrío, 400 de porcino, 100 de vacuno y 164 de distintos tipos de equino ${ }^{10}$.

De esta pequeñez del espacio útil a efectos productivos se derivan dos consecuencias. La primera, que la villa era dependiente del exterior para el abasto de prácticamente todo tipo de alimentos, salvo, quizá, de una parte de la carne y de los productos de huerta ${ }^{11}$. La segunda, que los bienes de propios del Ayuntamiento eran también escasos y, en consecuencia, insuficientes para cubrir con sus ingresos los gastos comunes. En la confluencia de ambas circunstancias se encuentra el sistema municipal de abastos, integrado durante los siglos XviI y xviII por una alhóndiga, una carnicería, una abacería y dos tabernas (tres, a finales del Setecientos).

Aunque el Ayuntamiento, por razones fiscales, regulaba y supervisaba el mercado de vino, las tabernas municipales no tenían el monopolio de su comercialización. Los establecimientos alternativos eran las tabernas eclesiásticas, fundamentalmente la del cabildo de la catedral, y los mesones. También se vendían algunas pequeñas cantidades de «vino aventurero» al por mayor. A todo ello habría que añadir, por supuesto, el vino que pudiera entrar clandestinamente, al margen de cualquier registro, para evitar el pago de impuestos.

En la taberna del cabildo, de la que durante algún tiempo se desgajó la taberna de los capellanes, en principio solo podían abastecerse los eclesiásticos, pero las autoridades municipales se veían obligadas a ejercer una vigilancia constante para evitar que los seglares accedieran a ella ${ }^{12}$. Con todo, a partir de los datos que recoge el Cuadro 1, cabe afirmar que las tabernas municipales constituyeron siempre la

9. Madoz, P.: Diccionario Geográfico-Estadístico-Histórico de Castilla y León. Soria. Valladolid, 1984, Ámbito, p. 91.

10. El Mapa $\mathrm{H}$ del Catastro ofrece unas cifras parecidas, pero no coincidentes: 4.251 cabezas de ovino, 483 de cabrío, 436 de porcino, 105 de bovino y 173 equinos.

11. Entre estos, el Catastro menciona la «pataca».

12. En las cuentas de tabernas de comienzos del siglo XviII aparece una partida para pagar a los encargados de vigilar e impedir que personas no autorizadas entraran en la taberna del cabildo.

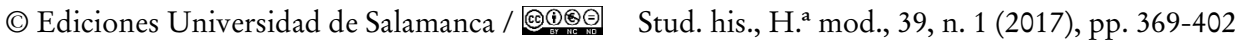


principal vía de suministro de vino para los habitantes de El Burgo de Osma. Esta posición se reforzó cuando, por real cédula de 21 de mayo de 1734, se dispuso el cierre de todos los puestos de abastos que tuvieran establecidos instituciones sujetas al fuero eclesiástico, cuyos miembros a partir de entonces deberían surtirse en los puestos públicos, aunque se les aplicaría una refacción en reconocimiento de la inmunidad eclesiástica ${ }^{13}$. En aplicación de dicha real cédula, el cabildo de la catedral de El Burgo de Osma clausuró su taberna -y también su «despensa de carne»- el 11 de junio de $1734^{14}$. A partir de ese momento, aproximadamente, el $90 \%$ del vino que se consumía en la villa debió de encauzarse por las tabernas municipales.

Cuadro 1: Distribución del vino consumido en El Burgo de Osma (en porcentaje por tipo de establecimiento)

\begin{tabular}{|c|c|c|c|c|c|}
\hline Años & \multicolumn{5}{|c|}{ Establecimientos } \\
\hline & $\begin{array}{c}\text { Tabernas } \\
\text { municipales }\end{array}$ & $\begin{array}{l}\text { Taberna del } \\
\text { Cabildo }\end{array}$ & $\begin{array}{c}\text { Taberna de } \\
\text { los Capellanes }\end{array}$ & Mesones & Vino aventurero \\
\hline $1611-1619$ & 66,2 & 18,5 & 2,5 & 12,6 & 0,2 \\
\hline \multirow[t]{2}{*}{ Años } & \multicolumn{3}{|c|}{ Solo tabernas } & & \\
\hline & Municipales & \multicolumn{2}{|c|}{ Eclesiásticas } & & \\
\hline $1611-1619$ & 76,5 & \multicolumn{2}{|c|}{23,5} & & \\
\hline 1675 & 74,6 & \multicolumn{2}{|c|}{25,4} & & \\
\hline 1731 & 76,9 & \multicolumn{2}{|c|}{23,1} & & \\
\hline \multirow[t]{2}{*}{ Años } & \multicolumn{5}{|c|}{ Establecimientos } \\
\hline & \multicolumn{3}{|c|}{ Tabernas municipales } & \multicolumn{2}{|c|}{ Otros establecimientos } \\
\hline 1795 & \multicolumn{3}{|c|}{88,7} & \multicolumn{2}{|c|}{11,3} \\
\hline
\end{tabular}

Fuentes: AMBO, Cuentas de millones (1611-1619) y cuentas de millones entre el cabildo y la villa $(1675,1731)$; «Liquidación de lo que debe pagar este pueblo por su encabezamiento, de los derechos de rentas provinciales...» (1795).

13. Gallardo, F.: Origen, progresos y estado de las rentas de la Corona de España, su gobierno y administración. Madrid, 1817, tomo I, pp. 42-47.

14. Archivo Histórico Provincial de Soria, 3157, Protocolos, 5386, fols. 67-68.

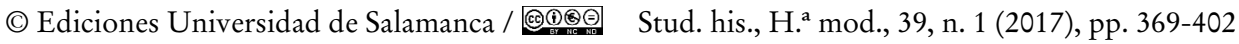


La gestión de las tabernas corría directamente a cargo del Ayuntamiento. Esta, para garantizar el suministro, se concertaba todos los años, mediante escritura, con arrieros obligados, que se comprometían a adquirir y acarrear el vino necesario; a tal efecto, podían recibir préstamos del administrador de las tabernas. El núcleo de las negociaciones entre la villa y los arrieros era el precio del transporte ${ }^{15}$. Al margen de este mecanismo, las tabernas ocasionalmente también admitían pequeñas partidas de «vino aventurero» que ofrecían arrieros no obligados.

Aunque había un administrador de las tabernas, era la corporación la que decidía de dónde había que traer el vino, en qué taberna debía venderse y a qué precio. Con objeto de recabar la información necesaria para tomar las decisiones de compra, el Ayuntamiento solía comisionar a alguno de sus miembros -normalmente, en noviembre, cuando ya estaba disponible el vino nuevo- para que recorriera las comarcas suministradoras y examinara las condiciones del mercado, reconociendo la calidad y el precio de los vinos -tanto los nuevos como los añejos- en los distintos lugares. Estos comisionados también se encargaban de verificar si los arrieros habían cometido algún fraude, en cuyo caso, el Ayuntamiento podía imponerles multas e instar el embargo de sus bienes e, incluso, su encarcelamiento ${ }^{16}$.

El Grafico 1 recoge las variables básicas del funcionamiento de las tabernas de El Burgo de Osma en un año cualquiera (1788): el número de arrobas de vino tinto que se descargaron cada día, su coste medio (el coste del vino en origen más el coste del transporte) y los precios de venta. A partir del mismo cabe hacer varias observaciones: 1) El aprovisionamiento de las tabernas precisaba de un flujo constante de vino, dado que aquellas carecían de instalaciones apropiadas para su almacenamiento en grandes cantidades y durante mucho tiempo. En promedio, cada tres días llegaban arrieros a descargar vino. Si suponemos que esta era la norma en la mayoría de los núcleos de población -y sin duda lo era en los más pequeños-, es evidente que el comercio de vino nutría una intensa y continua actividad de transporte. 2) La trayectoria anual del precio del vino se ajustaba a

15. El precio del transporte se negociaba anualmente y variaba según la procedencia del vino. Por ejemplo, los fijados para 1712 fueron de 10 maravedís por arroba y legua en el caso del vino blanco de Yepes, de otras partes de La Mancha y de Tierra de Madrid; de 7 maravedís para el tinto de La Mancha y Tierra de Madrid; de 6,5 (de enero a junio) y 6 (de julio a diciembre) maravedís para el tinto de la Alcarria. Para el vino procedente de la villa de Aranda el precio era de 64 maravedís por arroba y «de Aranda a abajo», 72 maravedís por arroba. Estas eran por entonces las principales áreas de abastecimiento. Pero se preveía la posibilidad de encargar a los arrieros vino de La Rioja o de Aragón, en cuyo caso se fijarían los precios correspondientes (AMBO, Actas del Ayuntamiento de El Burgo de Osma, 27 noviembre 1711).

16. AMBO, Actas, 28 agosto 1711.

(C) Ediciones Universidad de Salamanca / ®@ Stud. his., H. ${ }^{a}$ mod., 39, n. 1 (2017), pp. 369-402 
Gráfico 1: Cantidades de vino tinto descargadas en las tabernas de El Burgo de Osma, coste y precios de venta, 1788

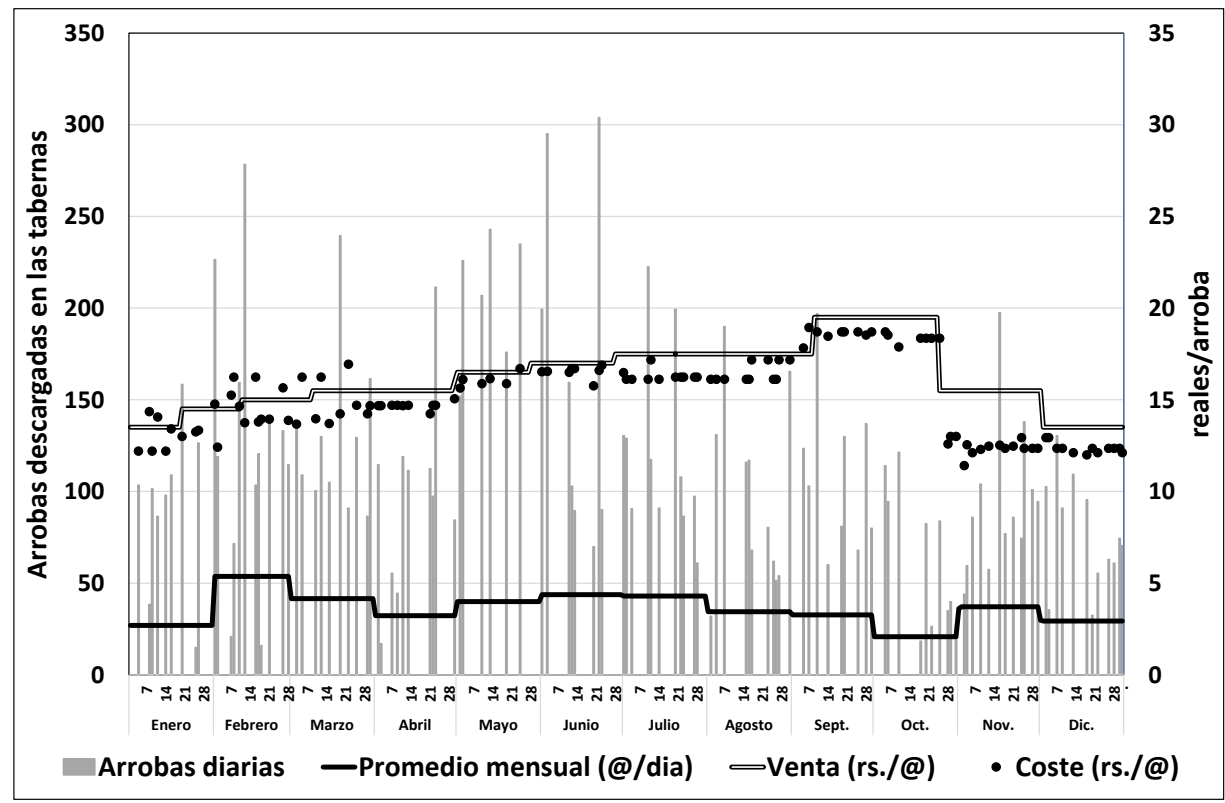

Fuente: AMBO, Libro de tabernas de 1788.

un marcado patrón estacional: descendía bruscamente en octubre o noviembre (en 1788 el coste del vino cayó casi un 30\% entre finales de octubre y comienzos de noviembre), es decir, aproximadamente un mes después de la vendimia, y seguía abaratándose hasta diciembre o enero, conforme iba saliendo el vino nuevo al mercado, para, desde comienzos de año, reiniciar un camino ascendente que culminaba entre septiembre y octubre ${ }^{17}$. 3) El precio de venta en las tabernas tendía a seguir la evolución del coste, pero no mecánicamente: el primero variaba menos y había momentos en que algunas partidas de vino se vendían a precios que no llegaban a cubrir su coste, en tanto que en otros -especialmente cuando llegaba el primer vino de la nueva vendimia- el precio de venta superaba con mucho al de adquisición. 4) La elasticidad precio de la demanda de vino parece ser muy rígida en lo que se refiere al patrón de consumo anual (en análisis mensual, -0,2).

17. El aumento del precio del vino entre diciembre-enero y octubre-noviembre se debía a que, simultáneamente, disminuía la oferta y aumentaba su calidad (vino añejo).

(C) Ediciones Universidad de Salamanca / ®@ Stud. his., H. ${ }^{a}$ mod., 39, n. 1 (2017), pp. 369-402 
El punto crucial de la intervención de las autoridades municipales radicaba en la fijación de los precios de venta -las posturas- de los distintos tipos de vino en cada momento. Los ingresos que el Ayuntamiento obtenía de las tabernas eran esenciales tanto para el pago del encabezamiento de impuestos reales como para la financiación de los gastos municipales y no cabe duda de que el vino era el producto cuyo consumo estaba más gravado.

\section{Una SERIE de precios del vino en las tabernas de El Burgo de Osma}

Como se ha apuntado más arriba, la elaboración de una serie de precios de vino no es una tarea sencilla. Las dos circunstancias que más la complican son la heterogeneidad del producto y el fraude. En efecto, dejando a un lado la diferencia fundamental entre mosto y vino, hay muchos tipos de caldos y, aun tratándose del mismo tipo de vino, la calidad podía variar tanto a corto como a largo plazo; en cuanto al fraude -cuya modalidad más común consistía en la incorporación de agua- es sabido que en algunos momentos fue masivo. La mayoría de las series de precios hasta ahora publicadas se han construido a partir de los libros de cuentas de una o varias instituciones, lo que, en principio, conjura o minimiza -aunque no elimina del todo- ambos problemas. Por otro lado, cuando se trata de comparar distintas series, hay que tener en cuenta otro factor no menos importante: la incidencia de la fiscalidad (variable en el espacio y a lo largo del tiempo) en cada una de ellas.

Por lo que se refiere a las dos Castillas, apenas contamos con más series de precios de vino que las recogidas por Hamilton y recientemente recuperadas por López Losa ${ }^{18}$ : media docena de series ${ }^{19}$, de las que solo dos, y no las mejores, son de la Meseta norte. En los últimos años, se ha añadido la de Andrés Ucendo para Madrid $^{20}$.

18. López Losa, E.: «The Legacy of Earl J. Hamilton. New Data for the Study of Prices in Spain, 1650-1800», Investigaciones de Historia Económica, 9, 2013, pp. 75-87. Una serie de precios del vino en Logroño, en Sáinz Ripa, E.: «Precio de los cereales, vino y oliva durante los siglos XVI, XVII, XVIII y XIX en Logroño y su comarca», Berceo, 106-107, 1985, pp. 7-38.

19. Alcalá de Henares (Madrid), Casarrubios del Monte (Toledo), Madrid, Mansilla (La Rioja), Toledo y Valladolid.

20. Enrique Llopis y Hector García Montero han recogido una nueva serie de precios del vino para Madrid (1680-1800) y David González Agudo otra para Toledo (1565-1650) (GonzáLEz Agudo, D.: «Población, precios y renta de la tierra en Toledo, siglos XVI-XVII», Tesis Doctoral, Universidad Complutense de Madrid, 2015), con objeto de elaborar sendos índices de precios, pero los datos no han sido publicados. Tampoco los de la serie de precios en origen de García Sanz para Fuentelcésped (Burgos) (1614-1846) (García SANZ, A.: «El vino de la Ribera del Duero: síntesis histórica (siglos XVI-XXI)», Revista de Jerez, 14/15, 2008-2009, pp. 91-105).

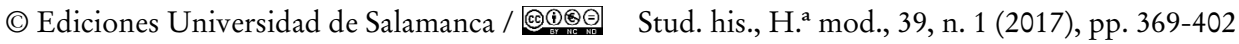


Gráfico 2: Precio del vino en las tabernas de El Burgo de Osma, 1655-1804

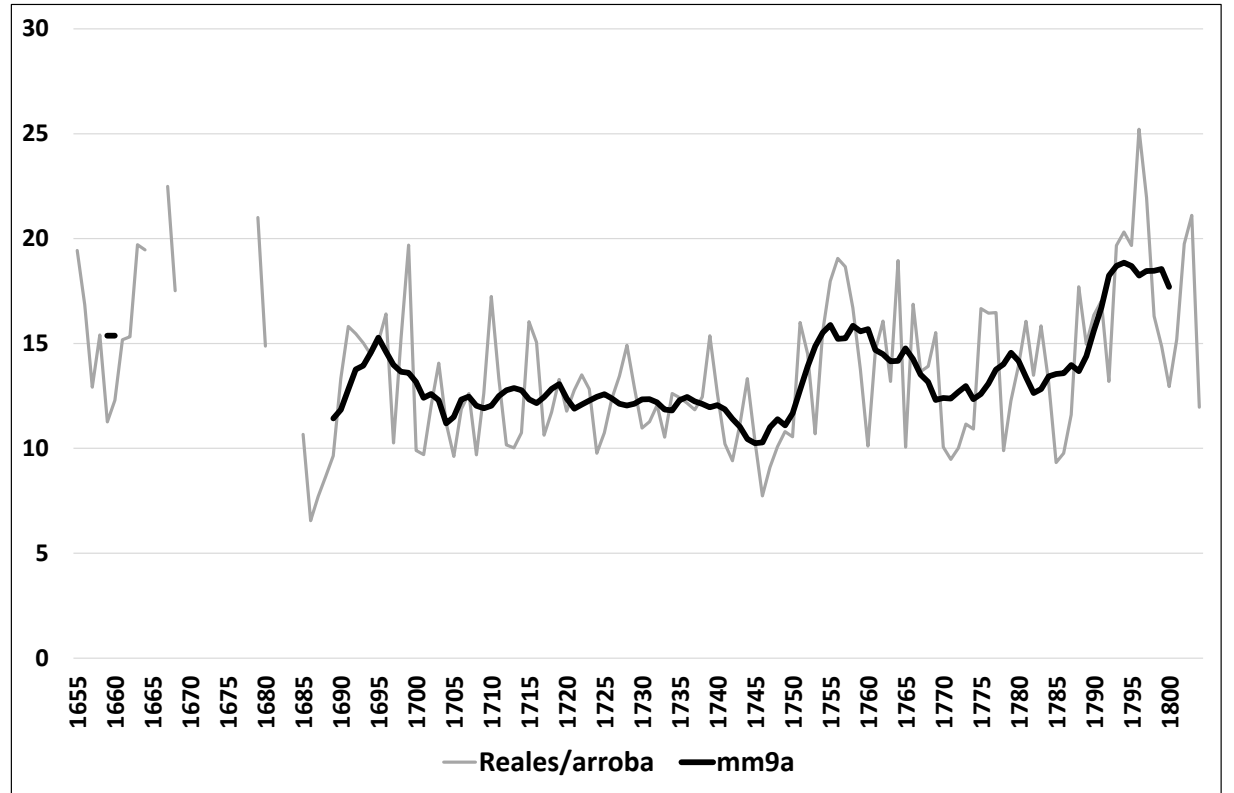

Nota: En este y en los siguientes gráficos «mmxa» = media móvil de $\mathrm{x}$ años.

Fuente: AMBO, Cuentas de tabernas.

La serie de precios del vino que aquí se presenta para El Burgo de Osma tiene ciertas diferencias con la mayoría de las mencionadas. Primero, es una serie de precios de venta al público (no a intermediarios ni a instituciones) al por menor ${ }^{21}$. Segundo, recoge los precios medios de una «cesta» de vinos cuya composición fue variando en el transcurso del siglo xviII en función de un amplio abanico de factores, entre otros los cambios en las preferencias de los consumidores. Tercero, cubre un porcentaje muy significativo del consumo de un mercado local (en torno al $66 \%$ hasta 1734 y casi el 90\% después). Estas dos últimas características restan relevancia al problema de la homogeneidad del producto. Cuarto, el fraude en lo que se refiere a la adulteración del vino - salvo que esta se produjera en origenno podía ser de importancia dado que en las cuentas de las tabernas coinciden siempre las cantidades de vino de la data -las compradas- con las el cargo -las vendidas-, dejando a un lado las pequeñas pérdidas que se producían cuando el

21. En el siglo xviıI, el $84,1 \%$ del vino que salió de las tabernas se vendió al por menor.

(C) Ediciones Universidad de Salamanca / ®@ Stud. his., H. ${ }^{a}$ mod., 39, n. 1 (2017), pp. 369-402 
vino se avinagraba, de las que también se deja constancia, puesto que en ese caso el producto solía trasladarse a la abacería. Y, quinto, es posible determinar con una precisión razonable qué porcentaje del precio se debía en cada momento a la carga tributaria.

A la vista del Gráfico 2, si ceñimos nuestro análisis al siglo xviII, se advierte que una vez superadas las tensiones alcistas que se produjeron en la última década del XVII, el precio del vino se mantuvo extraordinariamente estable durante toda la primera mitad del Setecientos, produciéndose, incluso, una ligera inflexión a la baja a finales del decenio de 1740. El panorama fue muy distinto en la segunda mitad del siglo: el vino se encareció durante toda la década de los 50 y buena parte de la de los 60; luego cayó, pero sin retornar a los niveles de partida, y volvió a subir desde la segunda mitad de los años 80 , hasta marcar los máximos del periodo en el tránsito del XVIII al XIX.

Entre 1701-1725 y 1776-1800 el precio del vino aumentó un 28\% en el Burgo de Osma; pero aún se habría encarecido más si, en ese mismo periodo, la penalización fiscal de su consumo no se hubiera reducido a la mitad.

Para medir la carga fiscal, he calculado en cuánto superaba el precio de venta al coste de adquisición y transporte del vino (Gráfico 3). Se trata de una medida aproximada porque no toda la diferencia se debía a los impuestos. Habría que descontar los costes de gestión de las tabernas (alquileres, salarios, administración...), pero estos eran pequeños: en la década de 1706-1715 no superaban el 3,5\% del precio de venta y, en términos relativos, debieron de disminuir, ya que se mantuvieron bastante estables mientras el vino se encarecía. Puesto que la remuneración de los taberneros -con mucha frecuencia, taberneras- está incluida en los costes de gestión, no hay que detraer beneficios derivados de la intermediación comercial.

El Gráfico 3 constituye, pues, una buena aproximación a la carga fiscal que soportaron los consumidores de vino al por menor en las tabernas de El Burgo de Osma. Atendiendo a las medias móviles de once años, los máximos se sitúan en la década de 1660, cuando llegó a superar el 40\%. La falta de información no nos permite saber qué ocurrió entre 1671 y 1684, pero los niveles de la segunda mitad de la década de 1680 son muy parecidos a los de veinte años antes. Entre 1685 y 1755 osciló entre el 25\% y el 30\%. A partir de 1745 (31,9\%) disminuyó rápidamente, hasta situarse en el $22 \%$ en 1757 . Luego se estancó durante una década, antes de proseguir una senda bajista que tocó fondo en 1793 (14,4\%), para luego moverse entre el 15 y el $17 \%$, con una tendencia ligeramente descendente hasta finales del primer cuarto de siglo xIX.

(C) Ediciones Universidad de Salamanca / @®@@ Stud. his., H. ${ }^{a}$ mod., 39, n. 1 (2017), pp. 369-402 
GrÁfico 3: Porcentaje del precio de venta del vino al por menor atribuible a las cargas fiscales (El Burgo de Osma, 1655-1825)

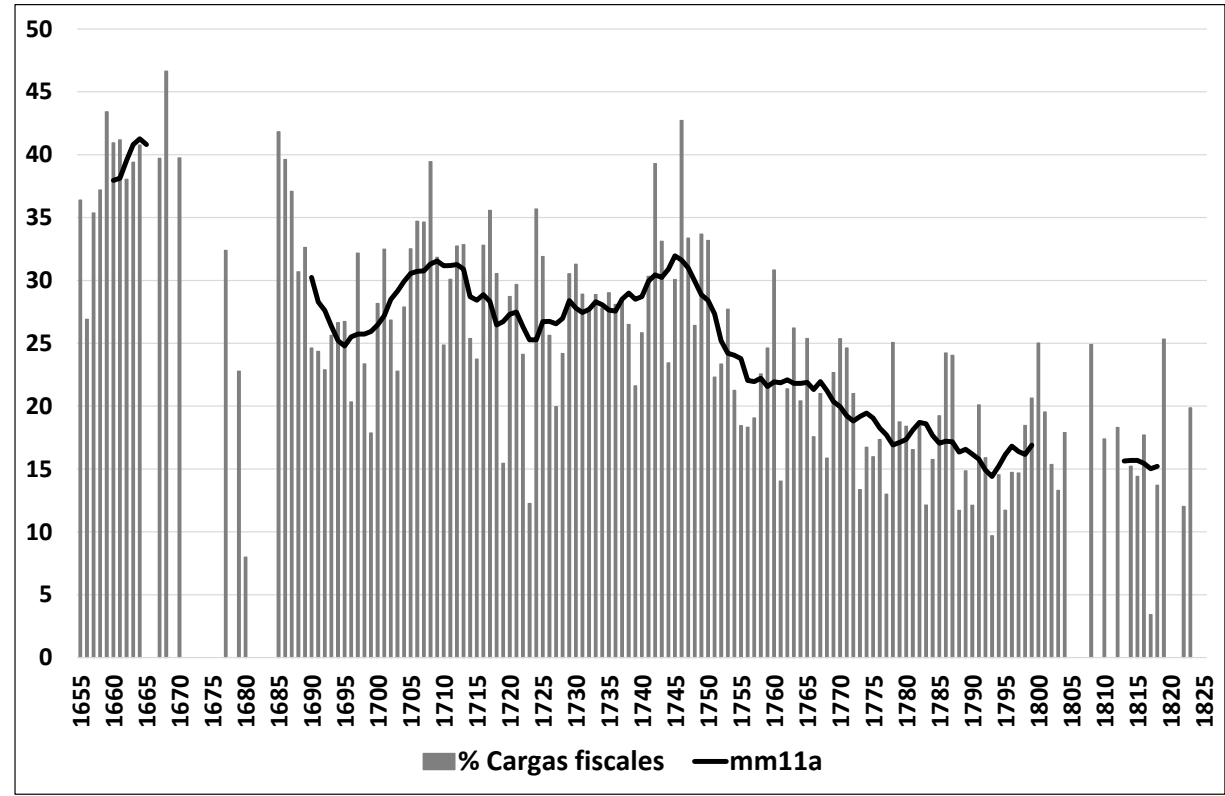

Fuente: $\mathrm{AMBO}$, Cuentas de tabernas.

En definitiva, durante la segunda mitad del siglo xviı, en El Burgo de Osma el precio de venta del vino tendió a aproximarse a sus costes, de modo que los consumidores dejaron de sufragar una parte de los gastos municipales. El inicio de ese proceso viene a coincidir con el primer salto en los precios, lo que podría revelar un intento por parte de las autoridades municipales de contener el encarecimiento del vino aligerando las cargas que gravaban su consumo. Esta reducción de la imposición sobre el vino implicó una disminución de la aportación neta de las tabernas a las finanzas municipales. Así, el porcentaje de la data de las cuentas de la villa cubierto por las tabernas fue descendiendo a lo largo del siglo XviII, pasando de algo más de la mitad a un tercio: $55 \%$ en $1701-1705 ; 41,6 \%$ en $1721-$ $1725 ; 37,0 \%$ en $1751-1755$ y $33,3 \%$ en $1796-1800^{22}$.

22. Este cálculo solo puede hacerse para los periodos de los que se han conservado tanto las cuentas de las tabernas como las cuentas generales de la villa.

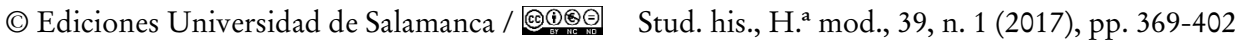


En principio, el gravamen sobre el consumo de vino debe relacionarse con el establecimiento de los millones. Y, efectivamente, hasta 1735, la administración de dicho impuesto estuvo vinculada a la de las tabernas, de modo que el pago de la «hijuela de millones» -y desde 1708 también la de «nuevos impuestos»-se cargaba directamente en las cuentas de dichos establecimientos. Ahora bien, una vez satisfechos los millones, quedaba un remanente que se transfería a las cuentas generales («propios y rentas»). Así se hizo hasta 1736, año a partir del cual el administrador de las tabernas pasó a entregar la totalidad de los beneficios que se obtenían en las mismas al receptor de propios, al tiempo que el pago de millones se trasladó a las cuentas generales.

En 1781, el Ayuntamiento afirmaba que «en el ramo de tabernas» no se exigía «cantidad alguna por vía de ganancia y sí solo el impuesto de millones o sisa, que de inmemorial tiempo» se recaudaba por dos vías. La primera, eran las ventas al por mayor, que se gravaban con dos reales por arroba en el caso de los vinos de Alcarria y Aragón, y con un real y medio en el de Aranda, salvo si los compradores eran eclesiásticos, en cuyo caso el recargo se reducía, independientemente del vino de que se tratase, a cinco cuartos por arroba (este descuento eximía al Ayuntamiento de compensar a los eclesiásticos con refacción alguna). La segunda, y fundamental, eran las ventas al por menor, en las que «se reduc[ía] la cántara de ocho azumbres a nueve y medio cuartillo", fijando el Ayuntamiento el precio del azumbre «según [lo] que prudencialmente juzga[ba] ser[í]a menester para la satisfacción del encabezamiento y otros gastos legítimos» ${ }^{23}$; es decir, aunque, de acuerdo con su origen, el propósito principal del gravamen sobre el vino era el pago de los millones, aquel se fijaba de tal modo que la recaudación permitía financiar otros gastos. Así, por ejemplo, en la primera década del siglo XviII en las cuentas de las tabernas se cargaban los 13.700 reales anuales que la villa pagaba por el servicio de millones (algo más si computamos los gastos administrativos anejos) y, a partir de 1708, otros 4.568 reales para satisfacer el encabezamiento de «nuevos impuestos»; pero entre 1701 y 1709, tras pagar los millones, el administrador de las tabernas pudo entregar al receptor de propios una media anual de 20.000 reales adicionales, que se transferían al cargo de las cuentas del Ayuntamiento, cantidad que representaba casi un tercio de los ingresos municipales. El Ayuntamiento contaba con una real facultad de 1589 que, en atención a la insuficiencia de sus propios, le permitía cargar en los abastos 6.237 reales y 26 maravedís, pero es evidente que la corporación exprimió mucho más a los consumidores de vino ${ }^{24}$.

23. AMBO, leg. 556, Libro de órdenes de propios y arbitrios, fols 257v-258. El subrayado es mío.

24. El vino siguió siendo uno de los productos preferidos a la hora de establecer nuevos gravámenes. En 1781, en virtud de real cédula, se estableció un impuesto de cuatro maravedís

(C) Ediciones Universidad de Salamanca / ®@ Stud. his., H. ${ }^{a}$ mod., 39, n. 1 (2017), pp. 369-402 
Gráfico 4: Precio del vino (en gramos de plata por hectolitro) en varias localidades de Castilla, 1650-1800 (medias móviles de 5 años)

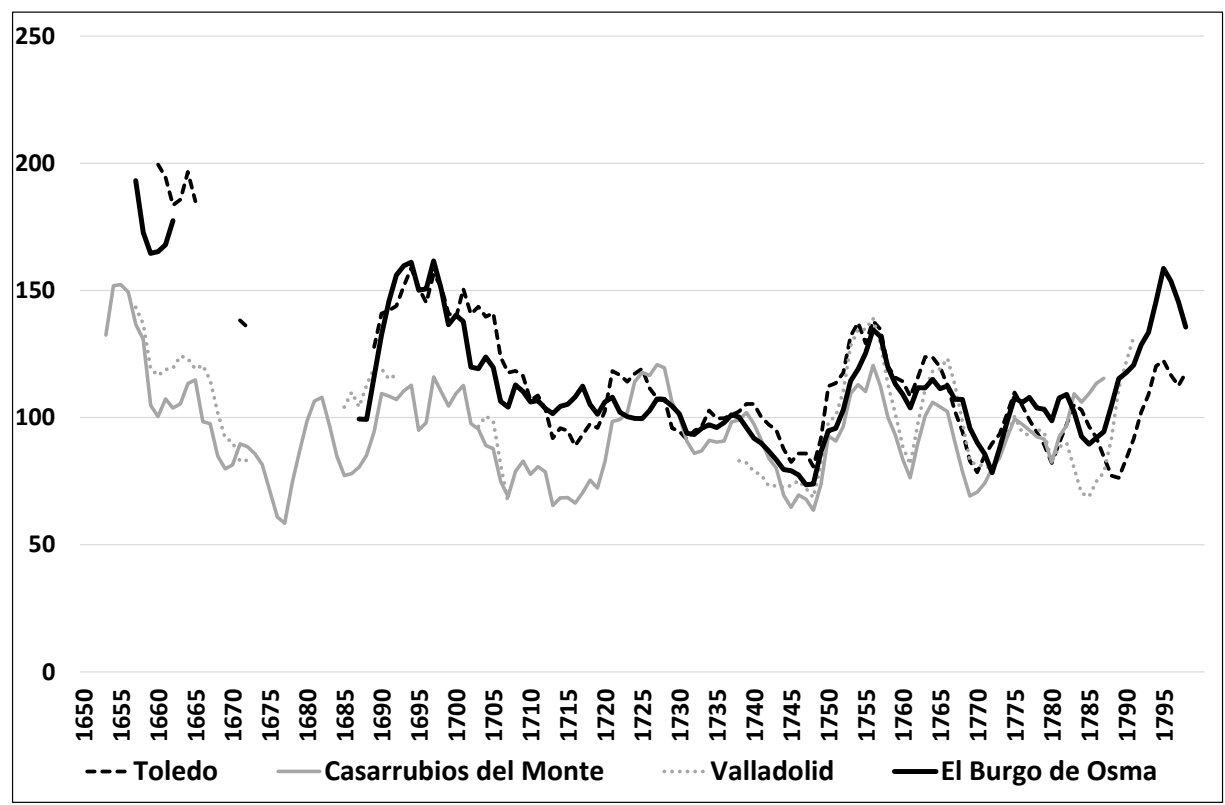

Fuentes: AMBO, Cuentas de tabernas y López Losa, E.: «The legacy of Earl J. Hamilton».

Si comparamos la de El Burgo de Osma con otras series de precios del vino correspondientes a localidades que podían compartir algunas áreas de aprovisionamiento con la villa burgense observamos que, a grandes rasgos, coinciden en la tendencia, pero que los niveles de precios difieren, de forma especialmente acusada en el siglo XVII, si bien se advierte una clara convergencia que parece culminar en los dos cuartos centrales del xviII. Dicha convergencia puede evidenciar tanto una

en cada cántara de vino cosechado o consumido en el territorio del obispado de Osma, como arbitrio para contribuir a la construcción de la capilla dedicada al venerable Palafox en la catedral de El Burgo de Osma (Loperráez, J.: Descripción bistórica del obispado de Osma, con tres disertaciones sobre los sitios de Numancia, Uxama y Clunia. Madrid, 1788, tomo 3, pp. 505-510). En principio, dicha carga se iba a mantener «por espacio de seis años», pero en 1821 seguía cobrándose (Diario de las actas y discusiones de las Cortes. Legislatura de los años de 1820 y 1821. Madrid, 1821, tomo XIII, p. 31). Desde comienzos de la década de 1780, también se cargaron otros cuatro maravedís en cada cántara de vino con destino a la reparación de caminos y puentes.

(C) Ediciones Universidad de Salamanca / ®@ Stud. his., H. ${ }^{a}$ mod., 39, n. 1 (2017), pp. 369-402 
cierta equiparación de la presión fiscal que soportaba el vino en las distintas localidades como una mayor integración del mercado. Las principales peculiaridades de la serie de El Burgo de Osma parecen ser una mayor estabilidad en la primera mitad del xviıI y un encarecimiento más agudo en el tramo final de la centuria, cuando las series divergen de nuevo. De las cuatro series consideradas, las dos que presentan el mayor coeficiente de correlación $(0,75)$ son las de El Burgo de Osma y Toledo.

Gráfico 5: Precios del pan y del vino en El Burgo de Osma, 1795-1800

(en números índices: $100=1701-1710$ )

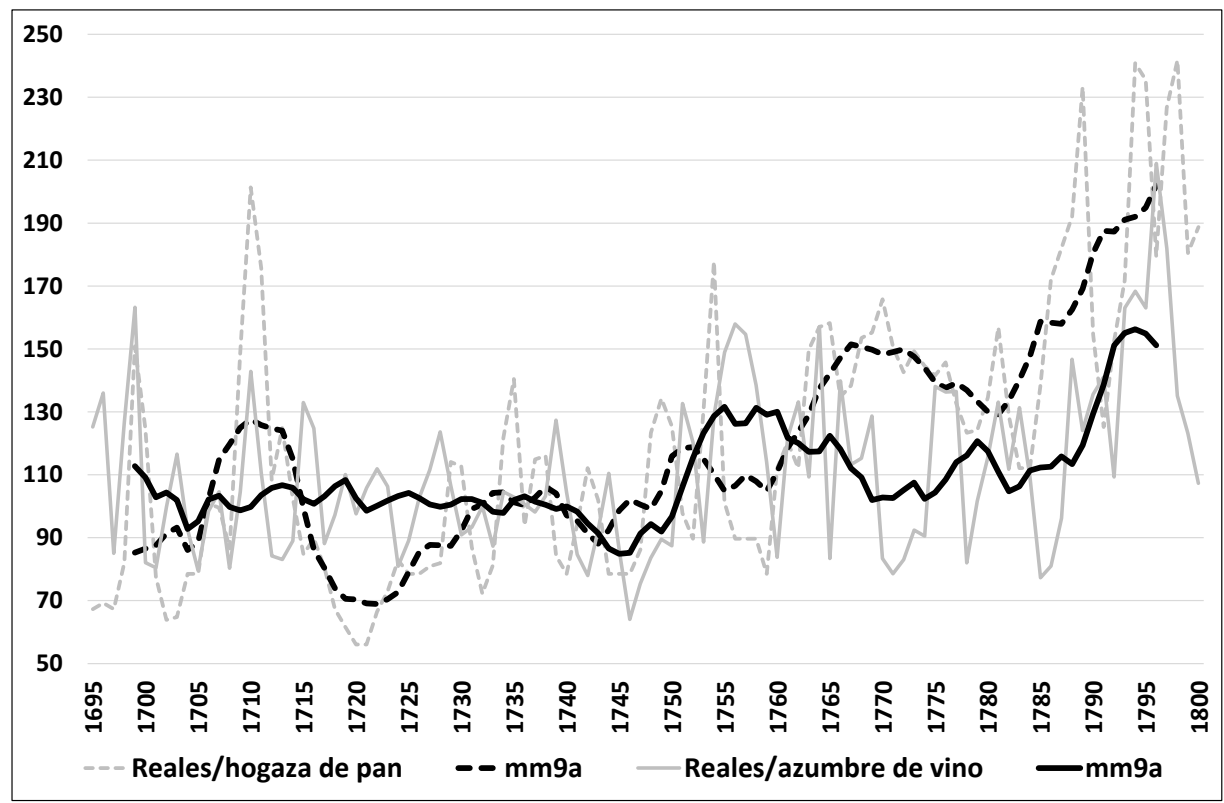

Nota. La serie de precios del pan se ha construido a partir de los precios fijados por el Ayuntamiento que figuran en los libros de acuerdos de la corporación. Se ha supuesto que las actas recogen todas las variaciones de precios, aunque lo más probable es que no sea así.

Fuentes: AMBO, Cuentas de tabernas y Actas del Ayuntamiento.

El Gráfico 5 muestra que el precio del pan creció todavía más que el del vino a partir de la década de 1760. ¿Cómo reaccionaron los consumidores de El Burgo a esta evolución de los precios? De forma inequívoca: la demanda de vino no solo disminuyó en términos per cápita sino que, pese al aumento del número de vecinos,

(C) Ediciones Universidad de Salamanca / ®@ Stud. his., H. ${ }^{a}$ mod., 39, n. 1 (2017), pp. 369-402 
también lo hizo en cifras absolutas. El consumo per cápita, que era relativamente alto, cayó desde los 132 litros por persona y año hacia 1752 hasta los 113 litros hacia 1787, y con posterioridad debió de seguir disminuyendo ${ }^{25}$. Entre la década de 1770, cuando en cifras absolutas se alcanzó un máximo en el consumo de vino en la villa, y la de 1790 se produjo una caída del 28\% (14.500 y 11.100 cántaras, respectivamente, en promedio anual), de modo que en el último decenio del xviII el consumo de vino, pese al crecimiento demográfico, probablemente había caído en más de un $20 \%$ en relación con la primera década del siglo ${ }^{26}$. La explicación de este comportamiento debe buscarse, probablemente, además de en la propia elasticidad precio de la demanda de vino (Gráfico 6), en un deterioro de la capacidad adquisitiva de los habitantes de la villa, especialmente de los perceptores de salarios en dinero.

Ahora bien, ¿podemos considerar el comportamiento de los consumidores burgenses como representativo de las zonas rurales de la provincia? Hay dos razones estrechamente relacionadas para dudar de tal representatividad: la primera es que entre los habitantes de la villa había pocos agricultores y la segunda, que el vino se abarató más en relación con el trigo que en relación con el pan ya que la intervención municipal tendió a amortiguar el encarecimiento de este. En consecuencia, en cuanto consumidores de vino, la situación debió de ser, en principio, más favorable para los productores de cereal que para los que no lo eran. En la medida en que aquellos intercambiaban trigo por vino y habida cuenta de que el producto cerealista por habitante permaneció bastante estable durante todo el siglo xviII en el área en torno a El Burgo de Osma ${ }^{27}$, cabe conjeturar que el consumo de vino pudo experimentar un estímulo, si bien no sabemos en qué medida fue contrarrestado por el aumento de la renta de la tierra y de la presión fiscal.

25. En Madrid, entre 1772 y 1778 se ha estimado un consumo de 47 litros por habitante y año (Palacio Atard, V.: La alimentación de Madrid en el siglo XVIII y otros estudios madrileños. Madrid, 1998, Real Academia de la Historia, p. 35). A finales del xviıI y comienzos del XIX, el consumo de vino era de 102 litros per cápita en Santander, 45 en Comillas y menor en otras localidades de Cantabria (LAnza, R.: Miseria, cambio y progreso en el Antiguo Régimen. Cantabria, siglos XVI-XVIII. Santander, 2010, PUbliCan, pp. 296-297).

26. Suponiendo que la parte del consumo total efectuado a través de las tabernas municipales era del 68 y el $88 \%$, respectivamente.

27. PÉrez Romero, E.: «Un mundo inmóvil. El producto agrícola por habitante en la cuenca alta del Duero durante la Edad Moderna», Investigaciones de Historia Económica, 14, 2009, pp. 69-102.

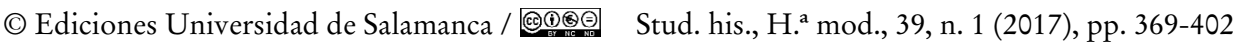


GrÁfico 6: Relación entre la evolución del precio y el consumo de vino per cápita en El Burgo de Osma (100 = 1745-1800)

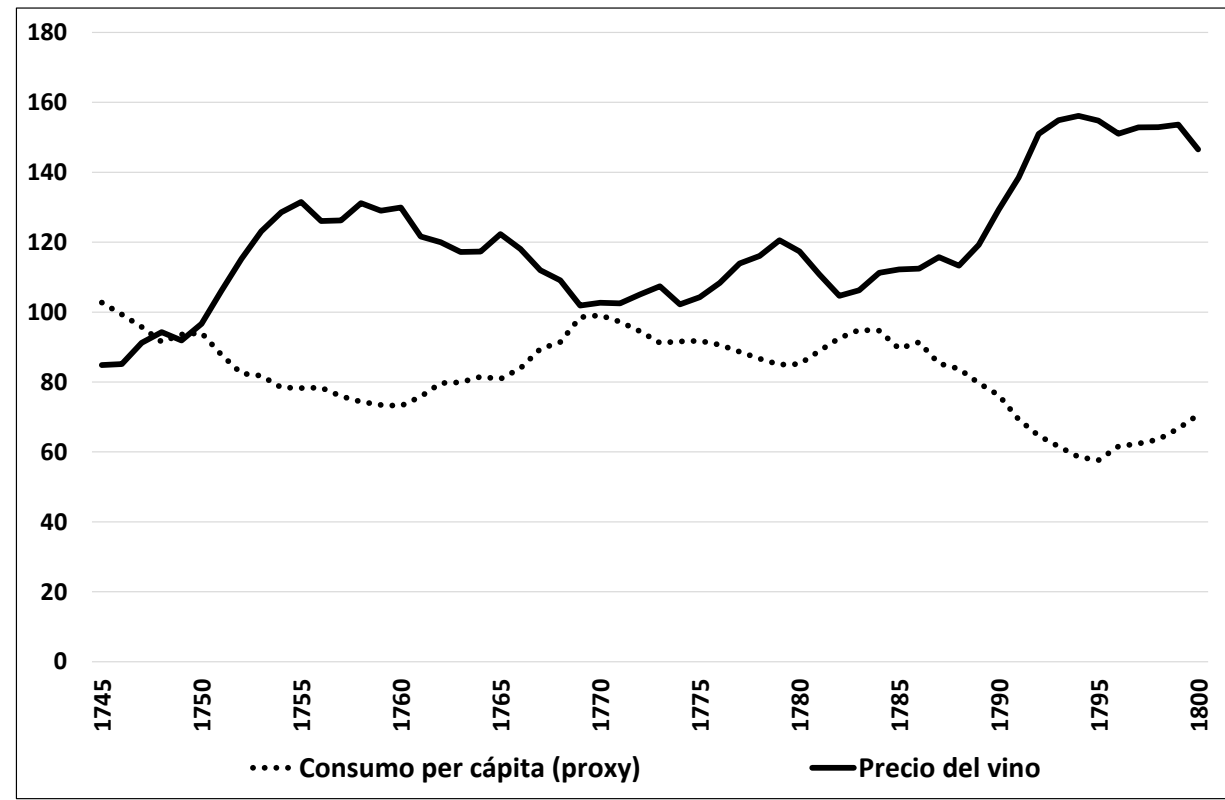

Nota. La proxy de consumo per cápita se ha elaborado a partir de las medias móviles de nueve años de un índice del vino consumido (numerador) y de las de un índice del número de bautismos registrados (denominador) en la villa; este último se utiliza, a su vez, como proxy de la población. El índice de precios del vino también aparece expresado en medias móviles de nueve años. El coeficiente de correlación de ambos índices (consumo per cápita y precios) entre 1685 y 1804 es -0,83.

Fuentes: AMBO, Cuentas de tabernas y AHDO-S, Libros de bautizados de El Burgo de Osma.

Lo cierto es que el aprovisionamiento de vino en los pequeños núcleos rurales respondía a características muy diferentes a las de El Burgo de Osma. A mediados del siglo xviII, según el Catastro de Ensenada, eran pocas las localidades ubicadas en el territorio de la actual provincia de Soria que contaban con una o varias tabernas -todas, por otro lado, de propiedad municipal-como establecimientos comerciales propiamente dichos. En la mayoría de los pueblos, el servicio de distribución del vino lo desempeñaban por turno - «por adra» y «por calle hita»- los vecinos en sus propias casas, sin que tal actividad les reportara, salvo excepciones, «utilidad» alguna, por lo que tampoco se les exigían «derechos». La distribución de vino al por menor no era, en general, un negocio sino una carga o servidumbre impuesta «por providencia de la justicia» para garantizar el abasto. Así lo presentan en muchas

(C) Ediciones Universidad de Salamanca / ®@ Stud. his., H. ${ }^{a}$ mod., 39, n. 1 (2017), pp. 369-402 
localidades las respuestas al Interrogatorio general. En el lugar de Tardelcuende, por ejemplo, se hace constar que «hay tienda, taberna, mesón y panadería, cuyos abastos y oficinas tienen cuatro vecinos respectivamente, uno cada cosa, y no se les puede regular ninguna utilidad al año por servirles más, si cabe, de daño que de provecho, y solo se usa de ellas para que haya abasto para los pobres y pasajeros» ${ }^{28}$. No obstante, los concejos sí que obtenían algunos ingresos por la venta de vino, pero estos procedían de los arrieros que abastecían a los pueblos. A este respecto, la situación general parece haber sido la que se describe en el pueblo de Izana, cuyo concejo percibía 24 reales «que paga el arriero que conduce el vino por la permisión de que lo pueda vender a coste y porte». Los 150 pueblos que integraban la Tierra de Soria, con una población de unos 24.000 habitantes percibían hacia 1752 en torno a 8.000 reales (unos 11 maravedís per cápita) por el comercio del vino $^{29}$, en su mayor parte pagados por los arrieros, lo que representaba apenas el $6 \%$ de todos los ingresos concejiles ${ }^{30}$. Los arrieros, naturalmente, incorporarían dichas cargas al precio del vino, pero su distribución al por menor no implicaba ningún encarecimiento posterior ya que, en general, la asumían gratuitamente los vecinos. En cualquier caso, lo realmente importante era que salvo en las localidades de mayor tamaño, en las que había tabernas, el consumo de vino no parece que estuviera especialmente gravado.

\section{ZONAS DE PROCEDENCIA DE VINO}

¿De dónde llegaba el vino que se consumía en El Burgo de Osma? Las fuentes proporcionan información al respecto aunque con un grado de detalle muy diferente según el periodo de que se trate ${ }^{31}$.

28. Los subrayados en las citas textuales de este párrafo son míos.

29. En 1752, el producto de las tabernas de El Burgo de Osma que el administrador de las mismas entregó al receptor de propios y rentas de la villa ascendió a 28.136 reales, lo que equivalía a unos 18,5 reales por habitante.

30. Pérez Romero, E.: Patrimonios comunales, ganadería trashumante y sociedad en la Tierra de Soria, siglos XVIII-XIX. Valladolid, 1995, Junta de Castilla y León, pp. 67-72.

31. A este respecto, pueden distinguirse cuatro etapas: 1) las cuentas del siglo XviI señalan casi siempre las zonas de procedencia del vino y a veces (salvo para la comarca de Aranda) las localidades concretas; 2) las cuentas de los años que van de 1701 hasta 1719 son las que proporcionan la información más precisa, en ellas los renglones de la data correspondientes a la compra de vino indican el lugar de procedencia de cada partida, de modo que es posible saber cuánto vino llegó desde cada lugar y a qué precios; 3) entre 1720 y 1738 , se vuelve a una práctica parecida a la del siglo xvir y las entradas solo identifican la zona de origen, pero no la localidad, y 4) de 1739 en adelante cada entrada podía englobar vino procedente de varias zonas distintas. Para algunos años de este último periodo se ha conservado una fuente

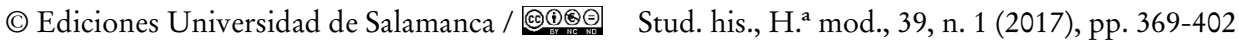


De cara al abastecimiento de vino, la opción más obvia para El Burgo de Osma era una de las principales zonas vitivinícolas de la Meseta norte: la Ribera del Duero; y lo era tanto por su proximidad como por el hecho de que buena parte de la misma pertenecía a la diócesis de Osma (los arciprestazgos de Gormaz, Aranda de Duero, Haza y Roa). Ahora bien, en la parte más oriental de dicha zona, la que se situaba dentro de la provincia de Soria, si bien la vid se cultivaba en muchos pueblos ${ }^{32}$, en general, la producción era tan pequeña que apenas alcanzaba a cubrir el consumo local: en total, a mediados del siglo xviII, puede calcularse una producción anual de 32.000 o 33.000 arrobas repartidas entre una veintena de localidades ${ }^{33}$. Había, pues, que adentrarse en la Ribera burgalesa para encontrar un área especializada en la producción y venta de vino. A mayor distancia se encontraban otras posibles zonas proveedoras: Navarra, Aragón, La Alcarria y La Mancha; también La Rioja, aunque las barreras orográficas eran en este caso mayores $^{34}$. Sin duda, las decisiones de las autoridades municipales en materia de abastecimiento debían de atender y combinar, en cada momento, tres tipos de consideraciones, que tenían que ver con los gustos y la capacidad adquisitiva de los consumidores, con la disponibilidad de vino en las distintas zonas en función de las cosechas, y con el coste del transporte.

Desde el siglo Xvir y hasta la segunda mitad del xviII, es decir, durante casi siglo y medio, en el mercado burgense predominaron de forma aplastante tres denominaciones de origen: una para el vino blanco, «vino de Yepes» (de La Mancha toledana), y dos para el tinto, «vino de Aranda» (o «de Aranda y su Tierra») y «vino de Alcarria», aunque a veces, esta última se ampliaba a «vino de Alcarria y Mancha». Por lo que se refiere al conjunto del siglo xviII, el 97,3\% del vino que pasó por las tabernas fue tinto.

Si consideramos todo el vino tinto registrado en las tabernas (tanto el vendido por mayor como el vendido por menor) en los 83 años para los que disponemos

alternativa, los libros de tabernas, que permite precisar de nuevo los lugares de procedencia, pero a costa de un trabajo desmedido, ya que es necesario procesar más de 600 entradas anuales.

32. Siguiendo el curso del Duero de este a oeste, se cultivaba la vid en los partidos de Berlanga, Gormaz y San Esteban de Gormaz, así como en algunas villas (Alcubilla del Marqués, Berzosa, Ines, Matanza, Rejas de San Esteban, Soto de San Esteban y Villálvaro).

33. Aproximadamente, un tercio de dicha producción se concentraba en la villa de Berlanga de Duero, que contaba con una población algo inferior a la de El Burgo de Osma. La información procede del Catastro de Ensenada.

34. Fuera de la mencionada zona de La Ribera, dentro del territorio de la actual provincia de Soria, la vid solo tenía una presencia significativa en su extremo sudoriental, dentro ya del valle del Ebro, en la comarca del Jalón. Allí, en poco más de una docena de localidades, a mediados del XviII difícilmente se producirían más de 20.000 arrobas.

(C) Ediciones Universidad de Salamanca / ®@ Stud. his., H. ${ }^{a}$ mod., 39, n. 1 (2017), pp. 369-402 
de información entre 1638 y 1738, resulta que 62,9\% llegó desde La Alcarria (Guadalajara) y La Mancha (Albacete, Ciudad Real, Cuenca y Toledo), entendiendo estas comarcas en sentido amplio ${ }^{35}$, mientras que el 35,9\% era vino de la Ribera del Duero (Burgos, Soria y Valladolid) y tan solo un 1,2\% tenía otras procedencias (La Rioja, Navarra y Zaragoza) ${ }^{36}$. Esta distribución resulta algo sorprendente si tenemos en cuenta que el vino de La Ribera era más barato tanto si atendemos a sus precios en origen como si consideramos el coste del transporte (Cuadro 2) ${ }^{37}$. Aunque la política de fijación de precios seguida por el Ayuntamiento perjudicaba en términos relativos a los consumidores de vino de La Ribera ${ }^{38}$, el predominio de los vinos de Castilla la Nueva solo puede atribuirse a dos factores de fondo: bien a una clara preferencia de los consumidores por el vino de La Alcarria y La Mancha, que era de mejor calidad, bien a una insuficiencia de la oferta de vino de La Ribera (o a una combinación de ambos). El hecho de que la proporción entre el vino de una y otra procedencia variase mucho de un año para otro (Gráfico 7) invita a subrayar la importancia de las condiciones de la oferta, al tiempo que revela una gran flexibilidad en el funcionamiento del sistema de abasto ${ }^{39}$.

El Cuadro 3 sintetiza la mejor información disponible acerca de la procedencia del vino. En él se recogen las provincias y las principales localidades desde las que llegó el vino que se vendió al por menor en las tabernas de El Burgo de Osma entre 1701 y 1719. El vino podía adquirirse muy lejos, tanto como en Sax (Alicante), pero esto solo ocurría excepcionalmente, cuando se producía una gran escasez en las zonas habituales de abasto ${ }^{40}$. El área normal de

35. Si nos atenemos a la delimitación comarcal del Ministerio de Agricultura (Caracterización de las comarcas agrarias de España), algunos de los pueblos desde los que llegaba vino a El Burgo de Osma pertenecerían a otras comarcas, como, por ejemplo, la Campiña en Guadalajara.

36. Entre 1655 y 1736, solo aparece vino de estas otras procedencias en 14 años, pero de estos en apenas cinco supera el 5\% del total: 1664 (9,3\%), 1692 (54\%), $1694(8,3 \%), 1710(9,8 \%)$ y $1716(17,8 \%)$.

37. Entre 1655 y 1736, en promedio, el coste del vino de Castilla la Nueva fue 57,5\% superior al de La Ribera (los costes del vino en origen y del transporte fueron, respectivamente, un $31,2 \%$ y un $149,5 \%$ mayores).

38. En el periodo indicado en las notas anteriores, el vino de La Ribera soportó, en promedio, una mayor penalización fiscal (un 33,3\% del precio final) que el de Castilla la Nueva (un $27,8 \%$ ).

39. Las desviaciones típicas de los porcentajes son de 21,8 y 22,1 para La Alcarria-La Mancha y la Ribera del Duero, respectivamente.

40. Ese debió de ser el caso de 1716, año en el que, además de la referida partida alicantina (29 arrobas por las que se pagaron 116 reales más 332,5 del coste de transporte), llegó a El Burgo vino de otras procedencias por entonces inusuales, como Aragón o La Rioja.

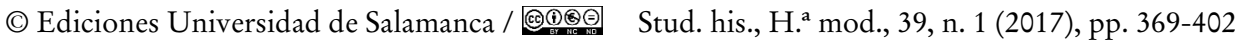




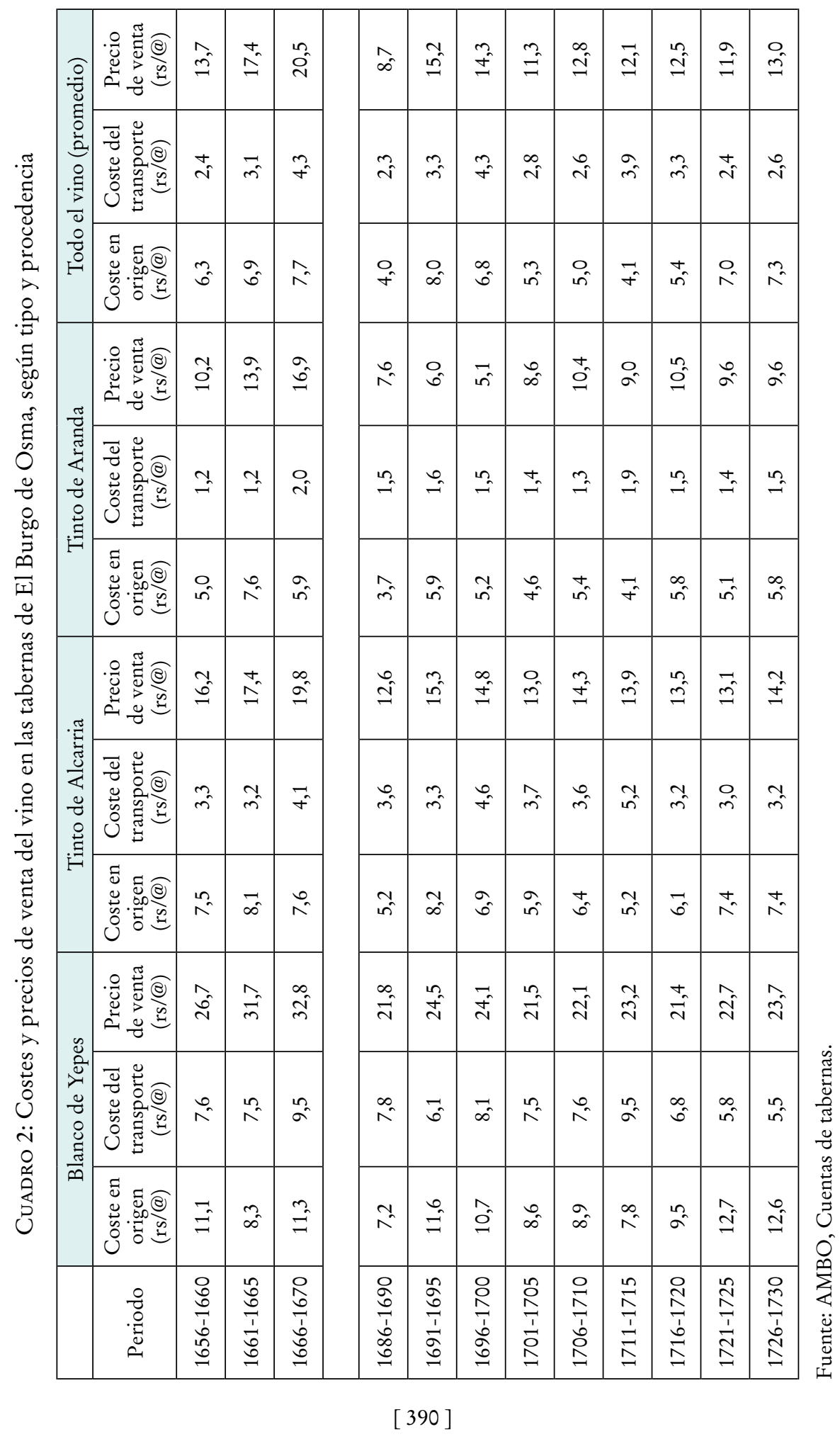



en las Tabernas de El Burgo de Osma, 1655-1736

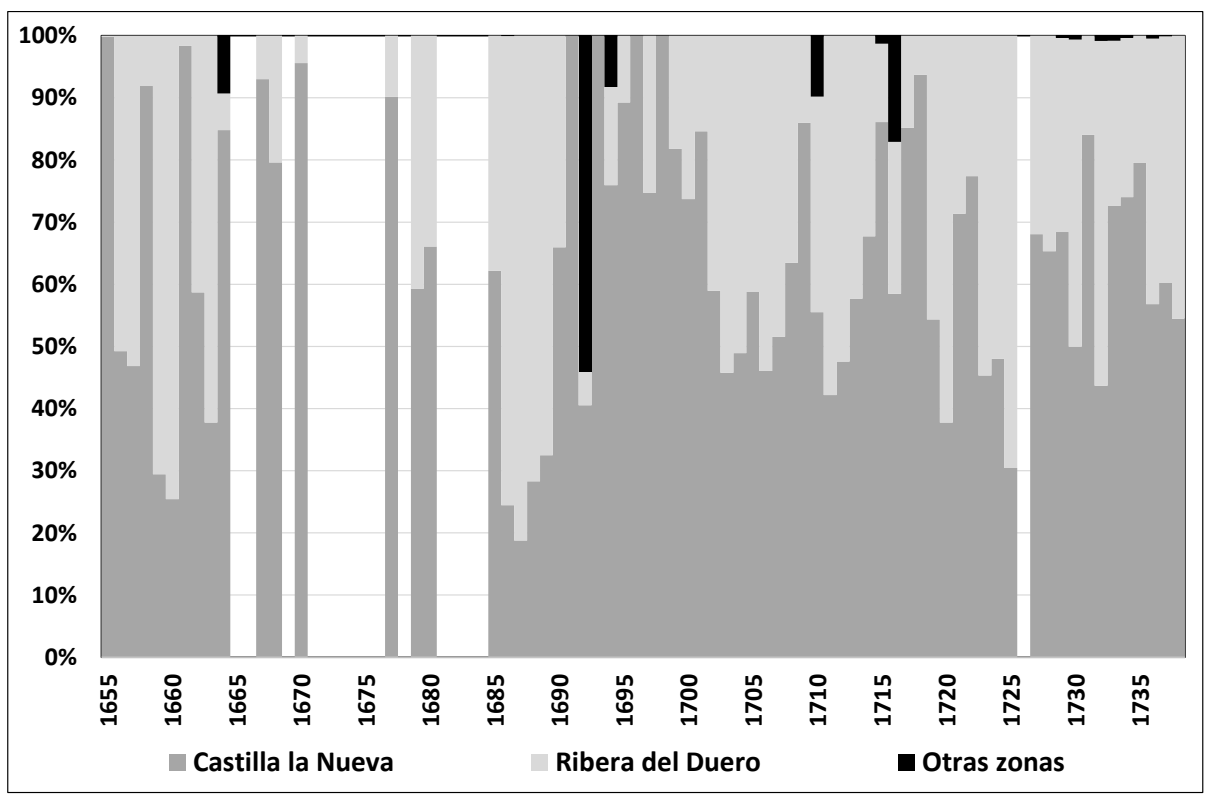

Fuente: AMBO, Cuentas de tabernas.

aprovisionamiento abarcaba cuatro provincias, desde las que llegaba vino todos o casi todos los años: por orden de importancia, Guadalajara, Burgos, Cuenca y Toledo (esta última por el vino blanco de Yepes), seguidas por Madrid. Ahora bien, las dos primeras proporcionaron en los 18 años analizados el $86 \%$ de todo el vino vendido en las tabernas. En definitiva, había un área potencial de abasto bastante amplia, que podía alcanzar los 375 kilómetros de distancia, pero el área habitual se movía entre los 50 y los 175 kilómetros, que son las distancias aproximadas entre El Burgo de Osma y los dos principales lugares de procedencia del vino: Vadocondes (19\%) y Sacedón (38,7\%). Aunque en los libros se pueden identificar hasta 76 localidades distintas, entre solo seis, de las dos zonas de referencia, la Ribera del Duero (Vadocondes, Fresnillo, Fuentespina y Aranda de Duero) y La Alcarria (Sacedón y Chillarón del Rey) proporcionaron el 78,5\% de todo el vino. En condiciones normales, se daba, pues, una notable concentración geográfica de las fuentes de suministro.

Entre 1739 y 1751 , aunque ya no es posible precisar su procedencia, las cuentas siguen refiriéndose casi exclusivamente a «vino de Alcarria» y «vino de Aranda». Sin embargo, en la segunda mitad del siglo xvirI se produjeron

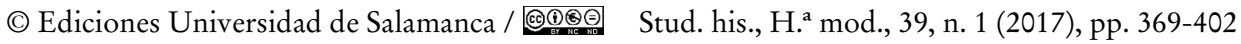




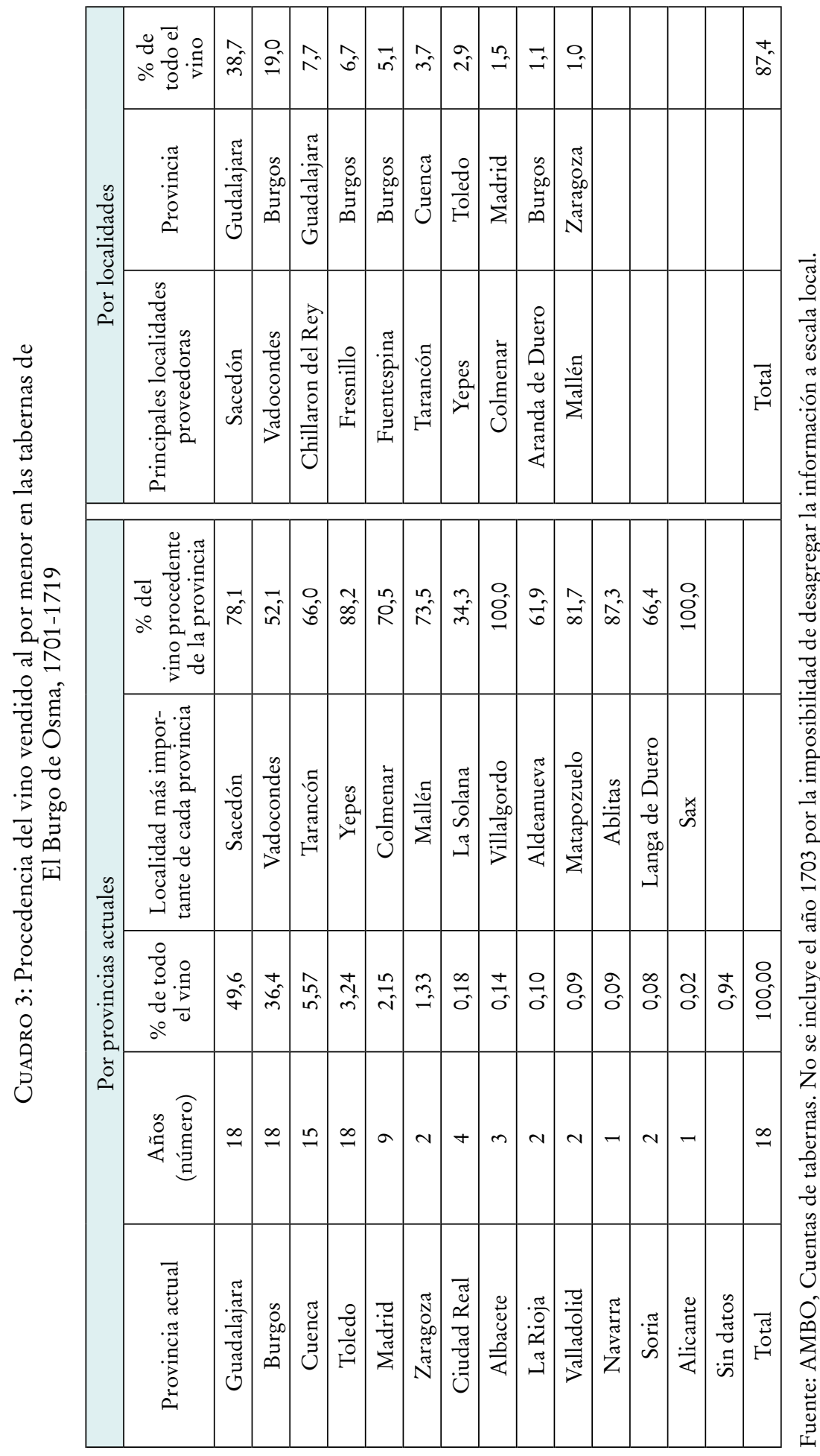


cambios importantes en el área de abasto ${ }^{41}$. A partir de 1752, empieza a mencionarse cada vez con mayor frecuencia el «vino de Aragón», primero en apuntes compartidos («vino de Alcarria y Aragón», «vino de Aranda y Aragón») o en partidas vendidas «por mayor». En 1764, el vino aragonés tiene, por primera vez, una entrada específica, lo que se repite en 1767 y, luego, de forma más regular, a partir de mediados de la década de 1770. Finalmente, entre 1784 y 1804, las cuentas solo mencionan el «vino de Aranda» y el «vino de Aragón». Es decir, en el transcurso de la segunda mitad del siglo xviII, la que había sido, cuando menos desde el primer tercio del siglo xviI, la principal zona de abastecimiento de vino para El Burgo de Osma, La Alcarria (y La Mancha), prácticamente desaparece y los caldos de dicha procedencia son sustituidos, primero, por un aumento del vino de la Ribera y, luego, lo que constituye la principal novedad, por el vino de Aragón. De hecho, entre 1784 y 1804, el 63,1\% del vino consumido en las tabernas de El Burgo fue vino aragonés, llegando a representar en la década de 1790 el $79,7 \%$ del total. Entre 1801 y 1804, volvió a predominar, brevemente, el vino de La Ribera (60,4\%), pero durante la guerra de la Independencia (1808-1814) este último prácticamente desapareció, cediendo de nuevo y de forma mucho más acusada el protagonismo al vino aragonés (94,2\%), que se consolidó después de la guerra (79,7\% entre $1815-1832)$.

La sustitución de Castilla la Nueva por Aragón puede tener tres explicaciones. Una por el lado de la demanda y dos por el de la oferta. Puesto que la progresiva desaparición del vino de La Alcarria coincide con los periodos en que el precio del vino experimentó un mayor incremento, podría achacarse a una búsqueda de vino más barato. Esta hipótesis podría dar cuenta del mayor consumo del vino de La Ribera, que era el de precio más bajo, pero no de la creciente importancia del vino de Aragón, ya que este tenía en las tabernas un precio muy parecido, si no idéntico, al de La Alcarria. En consecuencia, hay que considerar otras posibles explicaciones: 1) que en La Alcarria y La Mancha retrocediera la vid y

41. Los libros de tabernas que se han conservado correspondientes a la segunda mitad del siglo XVIII señalan cinco zonas como áreas potencialmente proveedoras, que denominan: «Tierra de Aranda», «La Alcarria», «La Mancha», «Tierra de Valladolid» y «Aragón». Las mayores novedades se encuentran en lo que se denomina «Tierra de Valladolid», que, pasando por Rueda, llega hasta Toro, y el amplio abanico de localidades aragonesas que figuran en la relación y que llegan hasta Zaragoza, fundamentalmente pertenecientes al Campo de Cariñena, al Campo de Borja y a la Ribera Alta del Ebro. El área de abasto, pues, se ha ampliado hacia el oeste y hacia el este, mientras que se ha acortado hacia el norte y hacia el sur: no figuran localidades de las actuales provincias de La Rioja y Albacete. No obstante, debe subrayarse que se trata de zonas a las que potencialmente podían dirigirse los arrieros obligados, pero en la práctica las áreas proveedoras estuvieron más concentradas, en el sentido que se indica en el texto.

(C) Ediciones Universidad de Salamanca / ®@ Stud. his., H. ${ }^{a}$ mod., 39, n. 1 (2017), pp. 369-402 
disminuyera la oferta de vino; 2) que el mercado madrileño acapararse una parte creciente de la producción vinícola de dichas comarcas, obligando a algunos antiguos clientes de las mismas a buscar áreas de suministro alternativas, que en el caso de El Burgo de Osma se habrían encontrado, fundamentalmente, en el Campo de Cariñena, que, según Jordán de Asso, era «el más dilatado viñedo de Aragón» ${ }^{42}$. Me inclino por la segunda, si bien los cambios que experimentó el área que abastecía de vino a Madrid en el transcurso del Setecientos no están bien documentados. Según Ringrose, fundamentalmente, se produjo un desplazamiento de las zonas de suministro hacia el sur. No obstante, la información cartográfica que proporciona dicho autor para el periodo 1750-1808 incluye localidades de la Alcarria que no aparecen en épocas anteriores ${ }^{43}$.

6. Algunas consideraciones en torno al efecto de los precios Sobre el CUltivo De la VID y LA TRAYectoria Del Mismo en la Ribera Del Duero DURANTE EL SIGLO XVIII

Es seguro que el deterioro de la relación de intercambio entre vino y trigo fue más acusado para los viticultores que para quienes concurrían a las tabernas, entre otras razones porque el precio del vino en origen cayó más, en términos relativos, que el precio a los consumidores. La cuestión es ¿ cómo reaccionaron los productores de vino? No estamos sobrados de información al respecto. En principio, la trayectoria de los precios relativos en la segunda mitad del siglo pudo inducir dos tipos de respuesta entre los viticultores: aumentar la producción para tratar de compensar la caída de los precios con un aumento de la cantidad que llevaban al mercado; o disminuirla, reasignando recursos a favor de la producción de cereales.

Lo cierto es que del deterioro del precio relativo del vino en relación con el del grano no puede deducirse, sin más, el efecto de una sustitución de vid por cereal. Al menos hay que considerar otro factor: la desigual productividad de ambos cultivos. El Catastro de Ensenada nos permite hacer algunos cálculos al respecto (Cuadro 4), con un resultado bastante concluyente: el rendimiento por

42. Jordán DE Asso, I.: Historia de la economía política de Aragón. Zaragoza, 1798, p. 159. La producción y el comercio de vino se ampliaron en Aragón a finales del siglo XviII; véase al respecto SAbio, A.: Los vinos de Cariñena, la casa de Aranda y la Ilustración económica aragonesa. Huesca, 1998, La Val de Onsera.

43. Ringrose, D. R.: Madrid y la economía española, 1560-1850. Ciudad, Corte y País en el Antiguo Régimen. Madrid, 1985, Alianza Editorial, pp. 236-257. Hay testimonios de que hacia 1824 en Madrid se consumía mucho vino de Sacedón (Mercado, J.; Moya, M. a J. y Herrera, A.: Historia de Sacedón. Patrimonio y costumbres. Guadalajara, 2003, AACHE Ediciones, p. 161).

(C) Ediciones Universidad de Salamanca / ®@ Stud. his., H. ${ }^{a}$ mod., 39, n. 1 (2017), pp. 369-402 
Cuadro 4: Comparación del producto monetario de una unidad de superficie de secano en vino y en cereal (sembrada de cereal $=100$ ) en varias localidades de la Ribera y de otras zonas vinícolas (c. 1752)

\begin{tabular}{|l|c|c|c|}
\hline \multirow{2}{*}{ Localidad } & \multicolumn{3}{c|}{ Calidad de la tierra } \\
\cline { 2 - 4 } & $1^{\text {a }}$ calidad & $2^{\text {a }}$ calidad & $3^{\text {a }}$ calidad \\
\hline Anguix & 195,5 & 351,0 & 348,4 \\
\hline La Horra & 78,3 & 136,9 & 418,6 \\
\hline Nava de Roa & - & 164,9 & 343,4 \\
\hline Olmedillo de Roa & 219,9 & 257,1 & 317,6 \\
\hline Roa & 247,1 & 329,4 & 388,9 \\
\hline San Martin de Rubiales & 153,1 & 131,3 & 220,5 \\
\hline Sotillo & 87,8 & 106,2 & 222,2 \\
\hline Sacedón & & 160,0 & 400,0 \\
\hline Yepes & 140,0 & 105,0 & 597,3 \\
\hline
\end{tabular}

Nota. La unidad de superficie en todos los pueblos es la fanega, pero su extensión varía de uno a otro y entre las distintas calidades de tierra. El cultivo de cereales en todos los pueblos de la Ribera era «a tercer año», lo que en esta y otras zonas de Burgos significa año y vez (ORTEGA, J.: La Bureba: estudio geográfico. Valladolid, 1966, Universidad de Valladolid, p. 72; ORTEgA, J.: La transformación de un espacio rural, las montañas de Burgos. Estudio de geografía regional. Valladolid, 1974, Universidad de Valladolid, pp. 166 y 168; Molinero, F.: La Tierra de Roa: la crisis de una comarca vitícola tradicional. Valladolid, 1797, Universidad de Valladolid, pp. 81 y 87, y CAMARERo, C.: «La producción agraria en el siglo XviII», Estudios Geográficos, XLV, 174, 1984, p. 90). El producto anual de la tierra se ha calculado multiplicando la producción media anual, teniendo en cuenta una rotación completa, por sus precios. Se ha estimado que el mosto experimentaba una pérdida del $25 \%$ en su transformación en vino (Huetz de Lemps, A.: Vino y viñedos de Castilla y León. Valladolid, 2004, Junta de Castilla y León, p. 521).

Fuente: Catastro de Ensenada, Respuestas Generales a las preguntas $4^{\mathrm{a}}, 5^{\mathrm{a}}, 9^{\mathrm{a}}, 12^{\mathrm{a}}$ y $14^{\mathrm{a}}$.

unidad de superficie a mediados del siglo xvirI, considerando tierra de la misma calidad, era notablemente superior si se explotaba con vides. En estas condiciones para estimular el descepe-que, además, acarreaba costes y no era fácilmente reversible- la evolución de los precios relativos no solo tenía que ser negativa sino que tenía que serlo de forma intensa y persistente. Es cierto que hay que tener en cuenta que el cultivo de la vid requería más trabajo y que la producción de vino precisaba de una cierta dotación de capital, pero en la coyuntura de la segunda mitad del siglo XVIII estos no debieron de ser factores decisivos: los salarios reales tendieron a deprimirse, una parte significativa del capital empleado en la industria vinícola era de propiedad colectiva y podía hacerse un uso más intensivo de las instalaciones disponibles. En cualquier caso, a la vista del Cuadro 4 cabe afirmar

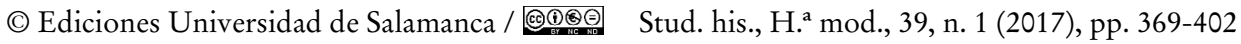


que solo en una parte de las tierras de mayor calidad -las más escasas- pudo ser rentable la sustitución de la vid por el cereal. Además no todas las tierras dedicadas al viñedo eran aptas para el cultivo de granos. Un factor que pudo condicionar la intensidad de este proceso de reconversión es el grado de separación entre la viticultura y la vinificación, algo de lo que no sabemos gran cosa.

Los pocos datos -no del todo satisfactorios- que he podido reunir ${ }^{44}$ sugieren que en una de las principales zonas suministradoras de vino a El Burgo de Osma, la de la Ribera burgalesa, la producción de vino tendió a aumentar ${ }^{45}$; lo cual es compatible con que disminuyera su peso relativo al crecer más rápidamente las cosechas de trigo. De hecho, algunos ilustrados criticaron la expansión del viñedo, denunciando incluso un problema de sobreproducción de vino.

Hacia 1788, en su Descripción histórica del obispado de Osma, Loperráez se lamenta de que en la parte del obispado correspondiente a la Ribera (los arciprestazgos de Aranda, Haza y Roa) «ya es raro el lugar donde se siembra, por haber hecho plantíos de viñas en las tierras que eran más propias para trigo y otras simientes». A este respecto, se hace eco del intento del obispo Bernardo Antonio Calderón, a comienzos de la década de 1770, de persuadir a los pueblos «para que dejando de plantar viñas fomentaran la agricultura y sementeras [...] hallando en los naturales mucha resistencia, por estar muy gustosos con el trato del vino»; y llega a proponer que «se prohibiera el plantar viñas de nuevo y se mandaran arrancar todas las que se han puesto de pocos años a esta parte». Loperráez sustenta su postura contraria a la expansión del viñedo ante todo en argumentos morales, subrayando que aquel fomentaba «en los naturales la mayor desidia y falta de aplicación»:

Conténtanse los de este país con solo el plantío y cultivo de las viñas, en lo que consumen una parte del año, estando lo restante desocupados, sin más destino ni ejercicio que visitar las bodegas, de que nacen los vicios, la pobreza y la miseria, que es notoria, causando mucha compasión por ver es oportuno el país para remediarla, si en los naturales hubiese la industria, aplicación y trabajo a que convida el terreno.

44. El Gráfico 8 muestra la evolución de los diezmos de mosto en los arciprestazgos de Aranda y Roa de la diócesis de Osma y de los correspondientes a la mitra en todo el obispado. Quiero dejar constancia de mi agradecimiento a Vanesa Abarca por haberme proporcionado los datos relativos a los diezmos burgaleses.

45. En el Apéndice gráfico de ANEs, G.: Las crisis agrarias en la España moderna. Madrid, 1970, Taurus, aparecen varias series de diezmos de mosto correspondientes a la Meseta norte, todas las cuales muestran una trayectoria ascendente desde la década de 1730.

(C) Ediciones Universidad de Salamanca / ®@ Stud. his., H. ${ }^{a}$ mod., 39, n. 1 (2017), pp. 369-402 
Gráfico 8: Diezmos de vino en la Ribera de Duero, siglo xviII

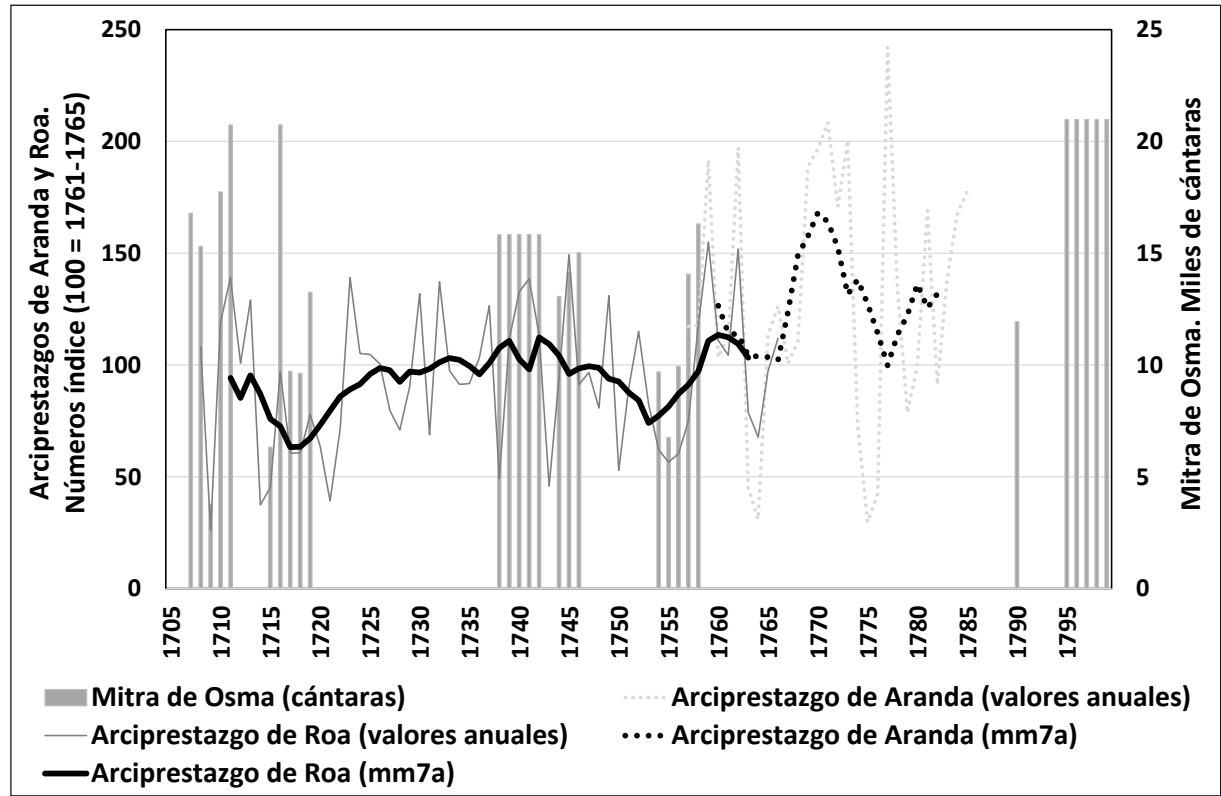

Nota. Por lo que se refiere a los diezmos de los arciprestazgos de Roa y Aranda se han estimado los datos de las cillas en los años en que faltan a partir de su peso relativo en los años más próximos para los que se cuenta con información completa, y las cantidades de vino se han homogeneizado en cántaras de ocho azumbres. En cuanto a los diezmos de la mitra de Osma por lo que se refiere a los quinquenios 1738-1742 y 1795-1799 no contamos con datos anuales sino solo con promedios. Fuentes: Archivo de la Archidiócesis de Burgos, libros de las particiones de cillas del arciprestazgo de Roa, 1708-1733 y 1734-1766; y Archivo Histórico Nacional, Consejos, legs. 17024 y 17025 (informes sobre las rentas de la mitra de Osma correspondientes a los años 1707-1711, 1715-1719, 1738-1742, $1744-1746,1754-1758,1790$ y $1795-1799)$.

También aducía razones económicas («lo que producen las viñas lo necesitan para pan en los años regulares, y que no les alcan[za] en los que tienen estimación los granos»), pero los datos expuestos y la misma resistencia de los afectados a cambiar la dedicación de sus tierras no parecen avalarlas ${ }^{46}$. Según Huetz de Lemps, en Aranda, el principal centro vitícola de la zona, para contener la expansión del

46. Loperráez también atribuía la falta de «vigor» y «fuerza» de los vinos de la Ribera a la deficiente elaboración de los mismos (Loperráez, J.: Descripción histórica del obispado de Osma, tomo 2, pp. 6-12).

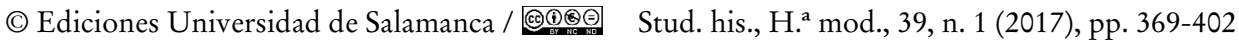


viñedo fue preciso que el Ayuntamiento prohibiera en 1782 plantar cepas en las tierras aptas para el cultivo del trigo ${ }^{47}$. No fueron, pues, los productores los que espontáneamente tomaron la iniciativa.

\section{Conclusiones}

La mayor parte del vino que se consumía en El Burgo de Osma en los siglos XVII y XVIII se vendía en las tabernas municipales: aproximadamente dos tercios del total hasta 1734 -año en que se cerró la taberna del cabildo de la catedral, en la que hasta entonces se surtían los eclesiásticos- y en torno al $90 \%$ a partir de entonces. El Ayuntamiento gestionaba el funcionamiento de las tabernas y determinaba la carga fiscal que debían soportar los consumidores de vino. Dichas cargas no se limitaban a cubrir el importe del impuesto de millones -su móvil inicial-, sino que proporcionaban una parte sustancial de los ingresos municipales.

La serie de precios de vino al por menor construida a partir de las cuentas de las tabernas muestra una gran estabilidad durante la primera mitad del siglo XVIII, seguida de un fuerte aumento, que se produjo, básicamente, en dos saltos: el primero durante la década de los 50 y buena parte de la de los 60 y el segundo a partir de la segunda mitad de los 80 . El vino se habría encarecido aún más si las autoridades municipales no hubieran aligerado de forma significativa, precisamente a partir de 1750, la penalización fiscal.

Aunque, en términos relativos, el vino se abarató dado que los precios de otros productos de consumo básico, como el pan, crecieron más, la respuesta de los consumidores burgenses fue reducir su demanda de vino, especialmente durante las dos últimas décadas de la centuria. A este respecto, debe subrayarse que la situación de los vecinos de El Burgo era distinta a la de la mayoría de las zonas rurales circundantes. En la villa apenas había productores de cereal ni, en general, agricultores, de modo que el aumento del precio del trigo no incrementaba su renta, pero sí deterioraba su capacidad adquisitiva, en la medida que los salarios se quedaban rezagados en relación con los precios. No sabemos cómo se comportó la demanda de vino allí donde predominaban los agricultores.

Durante el siglo Xvir y la primera mitad del XviII, el vino que se consumía en El Burgo, pese a la proximidad de una de las principales zonas productoras del valle del Duero, La Ribera burgalesa, procedía en su mayor parte (el blanco, casi en su totalidad) de La Alcarria y La Mancha. Así entre 1638 y 1738, que es

47. Huetz de Lemps, A.: Vino y viñedos de Castilla y León. Valladolid, 2004, Junta de Castilla y León, p. 257.

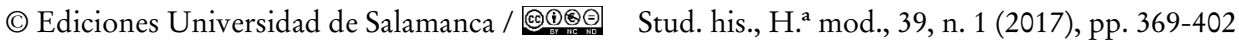


el periodo para el que podemos hacer los cálculos más afinados, apenas el 36\% del vino consumido en la villa procedía de La Ribera. No es posible determinar en qué medida esto se debía a las preferencias de los consumidores (el vino de Aranda era más barato, pero de peor calidad) o a las condiciones de la oferta en las distintas zonas.

En el transcurso de la segunda mitad del siglo se produjo un cambio sustancial en el área de aprovisionamiento: los vinos de Castilla la Nueva perdieron peso, hasta casi desaparecer, y, paralelamente, fueron ganándolo los de Aranda y -en esto radica la principal novedad- los de Aragón, fundamentalmente los del Campo de Cariñena, que acabaron convirtiéndose en los dominantes. Para explicar este cambio, la hipótesis más verosímil es que Madrid acaparó progresivamente los vinos alcarreños y manchegos, obligando a otras plazas que hasta entonces $-\mathrm{y}$, en algunos casos, durante mucho tiempo- se habían surtido en dichas comarcas a buscar nuevas zonas de suministro.

\section{APÉNDICE}

Precio medio anual del vino vendido al por menor en las tabernas de El Burgo de Osma, 1655-1823 (en reales por arroba)

\begin{tabular}{|c|c|c|c|c|c|c|c|}
\hline & reales/@ & & reales/@ & & reales/@ & & reales/@ \\
\hline 1655 & 19,4 & 1698 & 15,3 & 1741 & 10,2 & 1784 & 13,2 \\
\hline 1656 & 16,8 & 1699 & 19,7 & 1742 & 9,4 & 1785 & 9,3 \\
\hline 1657 & 12,9 & 1700 & 9,9 & 1743 & 11,2 & 1786 & 9,8 \\
\hline 1658 & 15,4 & 1701 & 9,7 & 1744 & 13,3 & 1787 & 11,6 \\
\hline 1659 & 11,3 & 1702 & 12,0 & 1745 & 10,4 & 1788 & 17,7 \\
\hline 1660 & 12,3 & 1703 & 14,1 & 1746 & 7,7 & 1789 & 15,0 \\
\hline 1661 & 15,2 & 1704 & 11,2 & 1747 & 9,1 & 1790 & 16,4 \\
\hline 1662 & 15,3 & 1705 & 9,6 & 1748 & 10,1 & 1791 & 17,0 \\
\hline 1663 & 19,7 & 1706 & 11,9 & 1749 & 10,8 & 1792 & 13,2 \\
\hline 1664 & 19,5 & 1707 & 12,6 & 1750 & 10,6 & 1793 & 19,7 \\
\hline 1665 & & 1708 & 9,7 & 1751 & 16,0 & 1794 & 20,3 \\
\hline 1666 & & 1709 & 12,6 & 1752 & 14,5 & 1795 & 19,7 \\
\hline 1667 & 22,5 & 1710 & 17,2 & 1753 & 10,7 & 1796 & 25,2 \\
\hline 1668 & 17,5 & 1711 & 13,3 & 1754 & 15,6 & 1797 & 21,9 \\
\hline 1669 & & 1712 & 10,2 & 1755 & 18,0 & 1798 & 16,3 \\
\hline
\end{tabular}

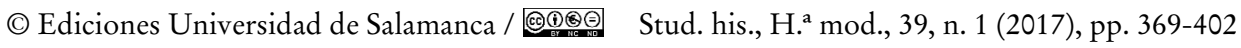


EMILIO PÉREZ ROMERO

ABASTO, PRECIOS Y CONSUMO DE VINO EN UNA VILLA CASTELLANA:

EL BURGO DE OSMA, 1655-1804

\begin{tabular}{|c|c|c|c|c|c|c|c|}
\hline & reales/@ & & reales/@ & & reales/@ & & reales/@ \\
\hline 1670 & 21,4 & 1713 & 10,0 & 1756 & 19,1 & 1799 & 14,9 \\
\hline 1671 & & 1714 & 10,7 & 1757 & 18,7 & 1800 & 12,9 \\
\hline 1672 & & 1715 & 16,0 & 1758 & 16,7 & 1801 & 15,2 \\
\hline 1673 & & 1716 & 15,1 & 1759 & 13,8 & 1802 & 19,7 \\
\hline 1674 & & 1717 & 10,6 & 1760 & 10,1 & 1803 & 21,1 \\
\hline 1675 & & 1718 & 11,7 & 1761 & 14,7 & 1804 & 12,0 \\
\hline 1676 & & 1719 & 13,3 & 1762 & 16,1 & 1805 & \\
\hline 1677 & 19,8 & 1720 & 11,8 & 1763 & 13,2 & 1806 & \\
\hline 1678 & & 1721 & 12,8 & 1764 & 19,0 & 1807 & \\
\hline 1679 & 21,0 & 1722 & 13,5 & 1765 & 10,1 & 1808 & 21,7 \\
\hline 1680 & 14,9 & 1723 & 12,8 & 1766 & 16,9 & 1809 & \\
\hline 1681 & & 1724 & 9,8 & 1767 & 13,7 & 1810 & 35,1 \\
\hline 1682 & & 1725 & 10,7 & 1768 & 13,9 & 1811 & \\
\hline 1683 & & 1726 & 12,4 & 1769 & 15,5 & 1812 & 39,1 \\
\hline 1684 & & 1727 & 13,5 & 1770 & 10,1 & 1813 & \\
\hline 1685 & 10,7 & 1728 & 14,9 & 1771 & 9,5 & 1814 & 33,4 \\
\hline 1686 & 6,6 & 1729 & 12,9 & 1772 & 10,0 & 1815 & 32,1 \\
\hline 1687 & 7,7 & 1730 & 11,0 & 1773 & 11,2 & 1816 & 25,0 \\
\hline 1688 & 8,7 & 1731 & 11,3 & 1774 & 10,9 & 1817 & 33,6 \\
\hline 1689 & 9,6 & 1732 & 12,1 & 1775 & 16,7 & 1818 & 26,4 \\
\hline 1690 & 13,3 & 1733 & 10,5 & 1776 & 16,4 & 1819 & 16,6 \\
\hline 1691 & 15,8 & 1734 & 12,6 & 1777 & 16,5 & 1820 & \\
\hline 1692 & 15,5 & 1735 & 12,4 & 1778 & 9,9 & 1821 & \\
\hline 1693 & 15,0 & 1736 & 12,1 & 1779 & 12,3 & 1822 & 11,7 \\
\hline 1694 & 14,5 & 1737 & 11,8 & 1780 & 13,9 & 1823 & 24,0 \\
\hline 1695 & 15,1 & 1738 & 12,5 & 1781 & 16,1 & & \\
\hline 1696 & 16,4 & 1739 & 15,4 & 1782 & 13,5 & & \\
\hline 1697 & 10,3 & 1740 & 12,6 & 1783 & 15,8 & & \\
\hline
\end{tabular}

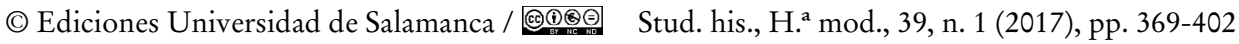


EMILIO PÉREZ ROMERO

ABASTO, PRECIOS Y CONSUMO DE VINO EN UNA VILLA CASTELLANA:

EL BURGO DE OSMA, 1655-1804

\section{BiBLIOGRAFÍA}

Álvaro Roldán, M.: «La ruta del vino en Guadalajara (siglos XVI-XIX). El papel predominante de La Alcarria», en CRIAdo DE VAL, M. (ed.): Actas del II Congreso Internacional de Caminería Hispánica, Guadalajara, AACHE Ediciones, tomo I, 1987, pp. 401-414.

Andrés Ucendo, J. I.: «¿Quién pagó los tributos en la Castilla del siglo XVIII? El impacto de los tributos sobre el vino en Madrid», Studia Historica. Historia Moderna, 32, 2010, pp. 229-257.

ANDrés UCENDO, J. I.: «Fiscalidad y precios en Castilla en el siglo XVII: los precios del vino en Madrid, 1606-1700», Revista de Historia Económica, XXIX, 2, 2011, pp. 269-298.

ANDRÉs UCENDO, J. I.: «Los precios del vino ordinario en el Madrid del siglo XVII», en Marcos Martín, A. (ed.): Hacer historia desde Simancas. Homenaje a José Luis Rodríguez de Diego. Valladolid, Junta de Castilla y León, 2011, pp. 53-72.

ANEs, G.: Las crisis agrarias en la España moderna. Madrid, Taurus, 1970.

CAmarero, C.: «La producción agraria en el siglo XVIII», Estudios Geográficos, XLV, 174, 1984, pp. 81-107.

Diario de las actas y discusiones de las Cortes. Legislatura de los años de 1820 y 1821. Madrid, 1821, tomo XIII.

Gallardo Fernández, F.: Origen, progresos y estado de las rentas de la Corona de España, su gobierno y administración. Madrid, Imprenta Real, 1817.

GARCía SANZ, Á.: «El vino de la Ribera del Duero: síntesis histórica (siglos XVI-XXI)», Revista de Jerez, 14/15, 2008-2009, pp. 91-105.

GonzÁlez Agudo, D.: «Población, precios y renta de la tierra en Toledo, siglos XVI-XVII». Tesis Doctoral, Universidad Complutense de Madrid, 2015.

Huetz de Lemps, A.: Vino y viñedos de Castilla y León. Valladolid, Junta de Castilla y León, 2004.

Jordán de Asso, I.: Historia de la economía política de Aragón. Zaragoza, 1798.

Lanza García, R.: Miseria, cambio y progreso en el Antiguo Régimen. Cantabria, siglos XVI-XVIII. Santander, PUbliCan, 2010.

Loperráez Corvalán, J.: Descripción histórica del obispado de Osma, con tres disertaciones sobre los sitios de Numancia, Uxama y Clunia. Madrid, 1788.

López Losa, E.: «The legacy of Earl J. Hamilton. New Data for the Study of Prices in Spain, 1650-1800», Investigaciones de Historia Económica, 9, 2013, pp. 75-87.

Llopis Agelán, E.; García-Hiernaux, A.; García Montero, H.; González Mariscal, M. y Hernández García, R.: «Índices de precios de tres ciudades españolas, 16801800: Palencia, Madrid y Sevilla», América Latina en la Historia Económica, 32, 2009, pp. 31-80.

Llopis Agelán, E. y GonZÁlez Mariscal M.: «Un crecimiento tempranamente quebrado: el producto agrario en Andalucía occidental en la Edad Moderna», Historia Agraria, 50, 2010, pp. 13-42.

(C) Ediciones Universidad de Salamanca / @®@@ Stud. his., H. ${ }^{a}$ mod., 39, n. 1 (2017), pp. 369-402 
Llopis Agelán, E. y García Montero, H.: «Precios y salarios en Madrid, 1680-1800», Investigaciones de Historia Económica, 7, 2011, pp. 295-309.

Fernández, J.: Caracterización de las comarcas agrarias de España. Tomo 21. Provincia de Guadalajara.Madrid, Ministerio de Agricultura, Alimentación y Medio Ambiente, 2012.

Mercado Blanco, J.; Moya Benito, M. a J. y Herrera Casado, A.: Historia de Sacedón. Patrimonio y costumbres. Guadalajara, AACHE Ediciones, 2003.

Molinero Hernando, F.: La Tierra de Roa: la crisis de una comarca vitícola tradicional. Valladolid, Universidad de Valladolid, 1979.

Ortega Valcárcel, J.: La Bureba: estudio geográfico. Valladolid, Universidad de Valladolid, 1966.

ORTEgA VAlCÁRCEL, J.: La transformación de un espacio rural, las montañas de Burgos. Estudio de geografía regional. Valladolid, Universidad de Valladolid, 1974.

Palacio Atard, V.: La alimentación de Madrid en el siglo XVIII y otros estudios madrileños. Madrid, Real Academia de la Historia, 1988.

Pérez Romero, E.: «Un mundo inmóvil. El producto agrícola por habitante en la cuenca alta del Duero durante la Edad Moderna», Investigaciones de Historia Económica, 14, 2009, pp. 69-102.

Ringrose, D. R.: Madrid y la economía española, 1560-1850. Ciudad, Corte y País en el Antiguo Régimen. Madrid, Alianza Editorial, 1985.

Sabio Alcutén, A.: Los vinos de Cariñena, la casa de Aranda y la Ilustración económica aragonesa. Huesca, La Val de Onsera, 1998.

SÁInZ RIPA, E.: «Precio de los cereales, vino y oliva durante los siglos XVI, XVII, XVIII y XIX en Logroño y su comarca», Berceo, 106-107, 1985, pp. 7-38.

Sebastián Amarilla, J. A.; García Montero, H.; Zafra Oteyza, J. y Bernardoos Sanz, J. U.: «Del crecimiento a la decepción. La producción agraria en Castilla la Mancha en la Edad Moderna. Una primera aproximación», IX Congreso de la AEHE. Sesión A1. El PIB y las macromagnitudes económicas en la España del Antiguo Régimen (Murcia, 10-12 de septiembre de 2008).

(C) Ediciones Universidad de Salamanca / @®@@ Stud. his., H. ${ }^{a}$ mod., 39, n. 1 (2017), pp. 369-402 